Journal Article

\title{
Life cycle analysis of steel railway bridges
}

D. Peng, A., Jones, R., Cairns, A., Baker, J., McMillan, A.

This article is published by Elsevier. The definitive version of this article is available at:

http://www.sciencedirect.com/science/article/pii/s016784421730246X

Repository record will be updated following publication

\section{Recommended citation:}

D. Peng, A., Jones, R., Cairns, A., Baker, J., McMillan, A. (2017), 'Life cycle analysis of steel railway bridges', Theoretical and Applied Fracture Mechanics, In Press, Corrected Proof. doi: 10.1016/j.tafmec.2017.06.023. 


\section{Manuscript Details}

Manuscript number

Title

Article type
TAFMEC_2017_232

LIFE CYCLE ANALYSIS OF STEEL RAILWAY BRIDGES

Research Paper

\section{Abstract}

This paper focuses on the growth of cracks that arise from natural corrosion in steel bridges. It is shown that these two effects of corrosion and stress, need to be simultaneously analysed. A methodology used to compute the growth of cracks that arise due to natural corrosion in bridge steels is presented. A better understanding of the remaining life of steel bridges will help establish an assessment procedure and guide engineers when deciding between reinforcement and replacement.

\section{Keywords}

Manuscript region of origin

Corresponding Author

Corresponding Author's

Institution

Order of Authors

Suggested reviewers steel bridges; corrosion; fatigue crack growth; remaining life

Asia Pacific

Rhys Jones

Monash University

Peng Daren, Rhys Jones, Ken Cairns, John Baker, Alison McMillan

Calvin Rans, Paulo de Castro, Andrea Carpinteri, Andrea Spagnoli, Loris Molent

\section{Submission Files Included in this PDF}

File Name [File Type]

Cover Letter.doc [Cover Letter]

New Reply to Reviewers Comments.docx [Response to Reviewers]

Revised Highlights 1.docx [Highlights]

Final Revised Manuscript TAM Special Issue.docx [Manuscript File]

Revised Figures.pdf [Figure]

Tables.docx [Table]

Marked up Final Revised Manuscript TAM Special Issue.docx [Supplementary Material]

To view all the submission files, including those not included in the PDF, click on the manuscript title on your EVISE

Homepage, then click 'Download zip file'. 
To Whom it May Concern

This paper is not being concurrently submitted for publication elsewhere. It is new research that has not been published elsewhere.

Professor Rhys Jones

Department of Mechanical and Aerospace Engineering Monash University

$11 / 05 / 2017$ 
Response To The Comments From The Editors And Reviewers:

- Reviewer 1

The Reviewer has accepted the paper. No modifications were required

\section{- Reviewer 2}

The only change needed was that the reviewer requested that Professor Filippo Berto's name to be removed from the list of authors.

\section{Reply: This has been done.}


- It reveals the importance of the interaction between material loss and fatigue

- It reveals the importance of allowing for small cracks

- It validates the AASHTO material loss model.

- It presents a methodology for assessing remaining life of steel bridges.

- It presents a combined numerical and experimental study. 


\title{
LIFE CYCLE ANALYSIS OF STEEL RAILWAY BRIDGES
}

\author{
D. Peng ${ }^{1}$, R. Jones ${ }^{1,2}$, K. Cairns ${ }^{1}$, J. Baker ${ }^{1}$, A. McMillan ${ }^{2}$ \\ ${ }^{1}$ Centre of Expertise in Structural Mechanics, Department of Mechanical and Aeronautical \\ Engineering, Monash University, Wellington Rd, Clayton, Vic 3800, Australia \\ ${ }^{2}$ School of Applied Sciences, Computing and Engineering, Wrexham Glyndwr University, \\ Mold Road, Wrexham, LL11 2AW, UK.
}

\begin{abstract}
This paper focuses on the growth of cracks that arise from natural corrosion in steel bridges. It is shown that these two effects of corrosion and stress, need to be simultaneously analysed. A methodology used to compute the growth of such cracks in bridge steels is presented. A better understanding of the remaining life of steel bridges would help establish an assessment procedure and guide engineers when deciding between reinforcement and replacement.
\end{abstract}

Keywords: steel bridges, corrosion, fatigue crack growth, remaining life

\section{INTRODUCTION}

Bridge condition can typically be expressed in two ways: condition appraisal (which is subjective) and analytical load rating. Condition appraisal is perhaps the most commonly used approach. The appraisal is a subjective rating based on established guidelines such as the National Bridge Inspection Standards (NBIS) and the inspector's judgment. Analytical load rating is also used to evaluate railroad bridges. The American Railway Engineering and Maintenance-of-Way Association (AREMA) publishes the Manual for Railway Engineering, which provides standards for railroad bridge evaluation [1]. In general, steel bridge structures must not only comply with enough strength but also behave satisfactorily under services loads ${ }^{1}$.

The assessment of the safety, durability and remaining life of steel bridges requires an understanding of the interaction of fatigue and corrosion degradation processes. In tension dominated members, there is a competition between the rate at which material is lost due to corrosion and the rate of fatigue crack growth. However, at present there is little information about the environments seen by Australian and Norwegian bridges or the associated rates of corrosion. In Australia the fatigue analysis of new and existing steel structures is based on the use of standardized S-N curves. To be able to provide an estimated life remaining for corroded steel bridge is very important for the infrastructure industry. A better understanding of the real behaviour of steel bridges would help establish an assessment procedure and guide engineers, when deciding between reinforcement and replacement.

Numerous publications can be found on corrosion fatigue, and a detailed discussion is provided in [2]. There are only a few available publications for solving the problems of

\footnotetext{
${ }^{1}$ In this context it should be noted that there are numerous approaches to repair cracking and degradation in steel bridges. Many different methods ranging from the stop drilling of holes [3-6] to the use of composite doublers $[6,7]$ are used.
} 
fatigue-corrosion interaction in steel bridges. A probabilistic approach and damage stress model to evaluate fatigue lives was developed in [8]. Many of the methods used focus on the use S-N curves for different atmospheric conditions coupled with assumed corrosion rates and simple cumulative fatigue damage laws [9, 10]. A fatigue crack growth evaluation method based on linear elastic fracture mechanics was developed in [11-15]. No available solutions can be found in the literature for corrosion-fatigue interaction where the section stress changes as material is lost due to corrosion.

Fatigue life prediction of corroded bridge steel beam is exceptionally difficult and computationally demanding, as calculations need to be made at each stage of the life of a beam. This is due to compute the stress intensity factor computations for each crack configuration that are needed to calculate the amount of crack growth, update the crack geometry, and then re-compute the stress intensity factors for this new geometry. To meet this challenge, this paper will discuss the issues associated with fatigue crack growth within corroded steel beam. The methodology addresses the following areas and develops the tools and procedures needed by industry:

1) A methodology for determining the load environment seen by steel bridges (i.e. the load spectra or load time history). It is illustrated by examining two bridges, viz: V/Line Brides 62 and Brides 44.

2) Tools for determining the operational environment seen by bridges.

3) A methodology for determining the corresponding rates of corrosion.

4) Tools for assessing the damage state of a bridge and for assessing the interaction of corrosion with the structure and the operational load spectra.

5) The fatigue crack growth tools which when coupled with an ability to monitor the rate of corrosion enable the operator to assess whether a bridge will fail via reduction in the net section or by fatigue crack growth. This then enables the operator to determine the appropriate maintenance periods.

In steps 4) and 5), a 3D model of the steel bridge beam without corrosion is created and the region of interest analysed. In this model, the crack is not explicitly modelled. Having determined the stress field with a semi-analytical solution technique [14, 17], conjunction with crack size modification factor and geometry evolution factor (varied with corrosion rate), was used to determine the stress intensity factors $(\mathrm{K})$ for any given crack length. These stress intensity factors were used in conjunction with the Hartman-Schijve crack growth equation [15, Error! Reference source not found.] to compute the crack growth history which can be thought of as a variant of the strain energy density formulation presented in [17, 18] and discussed in more detail in the Appendix. An advantage of this approach is that cracks in the structure do not need to be explicitly modelled. A crack of any size can be analysed using the original (un-cracked) finite element model. As cracks are not modelled explicitly, a coarser mesh can be used to minimise the number of degrees of freedom, thereby reducing the analysis time. Solutions for the stress-intensity factors can then be obtained for a variety of cracks using the original finite element analysis quickly and easily.

The data presented in this paper supports the ASHTO recommended metal loss model. The paper also reveals that the failure assessment of steel bridges needs to account for the 
interaction between fatigue crack growth and the stress increase created by corrosion due to the reduction in the section thickness.

\section{DETERMINING THE LOADING SPECTRA}

This section describes a method for determining fatigue analysis spectrum with REPOS (Road Environment Percentage Occurrence Spectrum) diagrams of Bridge 62 near 'Kilmore East', see Figure 1 and Bridge 44 (Western Line) near 'Little River', see Figure 2. The locations of the V/Line Bridges 62 and 44, both of which are just outside Melbourne, Victoria, are provided in Figure 3.

Figure 4 shows the selection of beams for Bridge 62 and the instrumentation of strain gauge as well as the location of the eight strain gauges, the inactive gauges for the half bridge arrangement and terminal blocks for connecting necessary wiring looms. The bridge has two rail tracks, each of which is supported by four girders with $4.87 \mathrm{~m}$ length. Four active strain gauges were installed on each beam. Additionally, a further eight strain gauges were bonded to two small plates which in turn were bonded to the webs of the reference beam and test beam. The purpose of these strain gauges was to make up one arm of the half bridge and compensate for any variation in temperature. The positioning of the active strain gauges was such that they could be considered as pairs. The active strain gauge pairs were 1 and 5,2 and 6,3 and 7,4 and 8 .

There are three bridges spanning a low lying area just east of Little River in Victoria. One of these bridges is managed by ARTC (Australian Rail Track Corporation). The other two bridges are managed by $\mathrm{V} / \mathrm{Line}$ (Australia's largest regional public transport operator). For ease of reference, the two V/Line bridges are called Bridge 44, see Figure 2. The UP line of Bridge 44 is supported by two girders with $6.57 \mathrm{~m}$ length. The rail track on the UP line (i.e. to Melbourne) is supported by spaced wooden sleepers which in turn are supported by two large girders. The rail track on the DOWN line (i.e. to Geelong) is supported by a concrete decking, all of which is supported by four girders. The UP and DOWN lines both have two spans. The fatigue analysis provided in this paper will focused on UP line of Bridge 44 . Figure 5 and Figure 6 show the selection of beams on which the strain gauges were installed. All strain gauges were located on the top side of the lower flange.

We first analysed the raw data of this module to assess the quality of the data. This was done using a Fast Fourier Transformation (FFT) to do frequency filtering. To further reduce the run time associated with fatigue analysis, the amplitude cutoff filtering technique was used to process the data after frequency filtering. Finally, a 'Rainflow' algorithm was employed to create the REPOS matrix.

The measured stress history associated with ore trains, see Figure 7, N-Class locomotives and Sprinter 1 are shown in Figures 8-10. The data was processed using FFT, see Figures 11-13. Noted: The sample rate was 0.002 and the Nyquist frequency was $250 \mathrm{~Hz}$. The dominant responses are below $\sim 50 \mathrm{~Hz}$, and the amplitude of the signal components is very much lower for frequencies higher than $50 \mathrm{~Hz}$. To remove electromagnetic or electrical noise that may have been recorded in the data acquisition, a low-pass digital filter was used to reduce the strain data recorded from the strain gauges. 
The "cutoff" frequency was chosen as $20 \mathrm{~Hz}$, see Figures $14-16$. It is obvious that the frequency filtering analysis techniques may not be good enough to eliminate all noises. Consequently another tool was used to remove this noise with lower amplitude.

This routine discards any cycles that are below a given threshold value. To analyse this data and extract the REPOS a generic rainflow program has been written. This program can handle any large data structure and was extensively validated against spectra obtained from the Australian Department of Defence and from General Motors. In this approach, it is assumed that the speed of the loading does not influence the fatigue life. The fatigue life prediction does not use the time variable of the signal. The data contained in the time series are taken at uniform time intervals. That means there are several data points between the peaks and valleys. It is necessary to use data reduction techniques, such as rainflow algorithm, to analysis the raw data. As the time series must only contain the peaks and valleys with no data points in between, a compression method called "peak and valley summary" has been used to delete these intermediate points from the time series. Also, there is no influence on the result of the bridge fatigue life prediction for the cycles in loading spectrum with small amplitude. As a result, another tool was used to further reduce the raw data. This routine discarded any cycles that were below a given a threshold value, while retaining the overall sequence of the loading.

The resultant "filtered" data will subsequently be used to perform bridge 62 near "Kilmore East' loading spectrum generation. The method for generating bridge 44 loading spectrum is the same as the method used for bridge 62. To minimise repetition, we have not provided the Load time history curve for the raw data and results of FFT for bridge 44 . The data of loading and train frequency for $\mathrm{V} /$ Line rail Bridge 62 and Bridge 44 have been gathered, see Table 1 . The Up line, i.e., the line towards Melbourne carried an estimated total of 1.17 and 0.833 million gross tonnes per year for bridge 62 and bridge 44 respectively, see Table 1 . These were made up of passenger trains, including trains pulled by $\mathrm{N}$ Class locomotives, sprinter carriages and ore train. The most heavily laden train is the ore train. It should be noted that all weights was in tonnes, the numbers listed in Table 1 were the average number of wagons or carriages. The ore trains were fully laden and the passenger trains only included normal passenger loads.

Figures 17 and 18 show the 3D distribution of the percentage of occurrences related to the "Bridge 62 near Kilmore East and Bridge 44 near Little River Load Spectrum". The represented by the REPOS ((Road Environment Percentage Occurrence Spectrum)) arrays used in this crack growth analysis.

\section{ENVIRONMENTAL DATA FROM BRIDGE 62}

The life of steel girder rail bridges is determined, in part, by corrosion and fatigue cracking. The sub-structure of the bridge was subjected to significant moisture and resulting corrosion during the wet seasons. Before assessing the coupled effect of corrosion and fatigue, a knowledge of the rate of corrosion is needed. In this paper, we will adopt the American Association of State Highway and Transportation Officials (AASHTO) recommended metal loss model [Error! Reference source not found., 20] which states that the metal loss versus time curve is bi-linear, see see Figure 19. However, as seen in Figure 19, there is little actual data to support this model and the data shown in Figure 19 is not particularly convincing. This approach to assessing the "steady state" corrosion rate is consistent with the International Standard Corrosion of Metals and Alloys - Corrosivity of Atmospheres, ISO 
designation 9224 [21], which specifies guiding values of corrosion rate for metals exposed to the atmosphere consisting of an average corrosion rate during the first 10 years of exposure. A detailed review of the corrosion of bridge steels, the AASHTO and ISO corrosion standards and documented steady state corrosion rates associated with a range of locations and steels is in given in [22].

One problem with aging bridges is that if there is any serious corrosion it is likely to have developed over a reasonable number of years. However, to know its significance we need to know how fast the bridge is corroding, i.e. its corrosion rate, at this moment in time. That said, we do not have the luxury of placing corrosion sensors or weight loss samples on a bridge and wait for 5 or more years until the sensors/samples themselves reach the steady state corrosion rate that the bridge is seeing.

The advantage of the AASHTO bi-linear approach is that once the bridge is behaving like the metal loss versus time curve on the line AB, see Figure 19, we know the long term corrosion rate without having to monitor the bridge for years. For bridges, this can be done in the order of four to twelve months using electrical resistance corrosion sensors [22].

In order to obtain the rate of corrosion, two University of South Australia (Uni SA) Data Loggers, Units 5 and 9, were installed on Bridge 44 in a stainless steel cage, see Figure 20. The loggers, with a primary aim of recording corrosion rates of attached corrosion sensor boards and environmental information, Data Logger software configuration was confirmed at V1.8 and both units had been proven serviceable. Unit 9 had an Australian Defence Science and Technology Group (DST Group) Sensor T1 installed in an exposed position between two sleepers to reduce physical damage and a CSIRO Time of Wetness [ToW] indicator wired into a Monash sensing circuit. Logger unit 5 had sensor BF10 installed in a sheltered position underneath a sleeper and then upside down.

Similar to Bridge 62, two Uni SA Data Loggers, Units Seven and Three, were installed on bridge 62 in a stainless steel cage. The loggers, were configured with V1.8 software and both had been proven to record and download data. Unit 7 had DST Group (Defence Science and Technology Group) Sensor (6F11), see Figure 21, installed in an exposed position on top of one of the beams supporting the exposed steel corrosion plates and a CSIRO (Commonwealth Scientific and Industrial Research Organisation) Time of Wetness [ToW] indicator wired into a Monash sensing circuit. Logger Unit 3 had sensor 5F10 installed in a sheltered position underneath the bridge deck on the same support pole but inverted.

The steel samples were attached to a "Skeleton" bridge structure and secured by two steel fasteners per plate. Two plates had a failed fastener each and had been realigned sideways. The ToW sensors were secured and suitably exposed. Data was downloaded from both loggers using the Uni SA Sensor Tool programme and the Graphical User Interface programme. The extreme vibration of the skeleton bridge could be the source. The data was downloaded multiple times to validate integrity. Raw data was downloaded with Uni S.A. "Sensor Tool" then extracted with "Data Extractor". The benefits of this process include less chance of corruption during the download and collation of all the sensor resistive values in one table rather than chronologically distributed through the data when extracted with the GUI. The GUI has been reissued to reduce but not eliminate this extra step.

The loggers were configured to record environmental information, temperature and relative humidity, every 30 minutes, whilst the absolute sensor resistance was measured every 24 hours. Environmental data consumed the bulk of data logger memory which translated to 
some two months for the $128 \mathrm{k}$ bytes. By reconfiguring the environmental sampling period from 30 minutes to one hour, the period between down loads can be extended to four months and this was done for all four data loggers. Visit periodicity is now determined by the risk of vandalism and data loss from vandalism.

The temperature reference strip on both exposed sensors is sealed in an epoxy sheath. The sheath is translucent and corrosion can be seen to be growing on both exposed sensors.

The corrosion rate data must be collected over an extended period to give an accurate value and the process cannot be hurried: this is the critical time path in the data collection process. The load data, the frequency of loading and how the load is applied must be gathered over a representative period to give reliable results. In the present study the load data and the lossof-material-to-corrosion data was collected over a period of approximately 18 months.

To illustrate this, Figures 22-24 present metal loss measured using a steel electrical resistance corrosion sensor at Monash in Metropolitan Melbourne, Bridge 44 on the Little River, which is on the coast between Melbourne and Geelong, and Bridge 62 at Kilmore East which is inland in Victoria, Australia, see Figure 3. Figures 22-24 substantiate the NCHRP (National Cooperative Highway Research Program) and AASHTO formulation and the advantage gained in real time monitoring of a rail bridge to obtain the long term corrosion rate. The steady state corrosion rates determined in these tests are presented in Table 2 . These rates are consistent with those documented in [22].

The results of this study support the AASHTO standard for the loss of metal seen by steel bridges. As such, the AASHTO bi-linear relationship between metal loss and the time in service provides a simple method for estimating the corrosion rates associated with aging structures. It is also shown that corrosion sensors can be used to determine the metal loss versus time relationship and hence can play an important role in any bridge management system.

\section{FATIGUE CRACK GROWTH WITH CORROSION EFFECT MODEL}

\subsection{Failure Due To Material loss (Corrosion)}

Corrosion of steel bridge girders will be a maximum where electrolyte can "wick" between the transom and the girder compression flange or where electrolyte is trapped by some other means. The worst case scenario is loss of material from the web, top flange and bottom flange. A graphical representation of the corroded I beam as well as a diagram showing a semi-elliptical crack in corroded I beam is provided in Figure 25. The dimension of the girders are given in Table 3. From direct measurement, the top side of the lower flange fibre stress for bridge 62 is $50.3 \mathrm{MPa}$ and for Bridge 44 is $62.3 \mathrm{MPa}$ respectively.

The distance from the beam neutral axis to the extreme flange fibre $y_{c}$ and the Moment of Inertia about the neutral axis I can be calculated from the relation

$$
\begin{gathered}
y_{c}=\frac{\sum_{i=1}^{5} t_{i} B_{i}\left(\sum_{j=1}^{i-1} t_{j}+\frac{t_{i}}{2}\right)}{\sum_{i=1}^{5} t_{i} B_{i}} \\
I=\sum_{i=1}^{5}\left\{\frac{B_{i} t_{i}^{3}}{12}+B_{i} t_{i}\left[y_{c}-\left(\sum_{j=1}^{i-1} t_{j}+\frac{t_{i}}{2}\right)\right]\right\}
\end{gathered}
$$


The outer flange fibre stress in beams subject to bending can be:

$$
\sigma_{L}=M y_{c} / I
$$

where $\sigma$ is the stress, $\mathrm{M}$ is the applied Moment. The shear stress at point $L_{l}$ as shown in as Figure $25 \tau_{L_{1}}$.

$$
\tau_{L_{1}}=Q S^{*} /\left(I B_{3}\right)
$$

Where $S^{*}$ is first moment of the area and it can be calculated from the equation

$$
S^{*}=\sum_{i=1}^{2} t_{i} B_{i}\left(y_{c}-\frac{t_{i}}{2}\right)-t_{1} t_{2} B_{2}
$$

The normal stress at point $L_{1}$ as shown $\sigma_{L_{1}}$ can be easy obtained from equation (5):

$$
\sigma_{L_{1}}=M\left(y_{c}-t_{1}-t_{2}\right) / I
$$

Let's name the maximum principle stress at points $\mathrm{L}$ and $\mathrm{L}_{1}, \sigma_{L}$ and $\sigma_{1}\left(L_{1}\right)$. Then, the stresses $\sigma_{L_{1}}$ and $\tau_{L_{1}}$ can be used to calculated the stress $\sigma_{1}\left(L_{1}\right)$. Therefore, the maximum stress in I beam is given by

$$
\sigma=\operatorname{Max}\left[\sigma_{L}, \sigma_{1}\left(L_{1}\right)\right]
$$

The limits are the as-new girder measured stress and the material yield stress. If the measured corrosion rate for bridge steel I beam is $\xi$ (mm/year), the maximum stress in I beam $\sigma$ is function of the corrosion rate $\xi$. From the equation of $\sigma=\sigma_{y}\left(\sigma_{y}\right.$ is the yield stress for the steel), the relationship between the flange stress, allowing for the loss of material due to corrosion, and operational life can be obtained.

The relationship between the maximum stress, allowing for the loss of material due to corrosion, and operational life are given in Figures 26 and 27. The yield stress for this steel was conveyed by V/Line staff to be approximately $240 \mathrm{MPa}$. This implies that retirement resulting from corrosion from an as-new state is approximately 244 years for Bridge 62, see Figure 26(a). Whilst in bridge 44 is approximately 250 years, see Figure 27 (a). It is also obvious that the loss of girder material due to corrosion has more effect on the web, than on the flange. This causes a larger percentage decrease in shear capability, than in bending capability for Bridge 62 . Whilst in bridge 44, stress at point $\mathrm{L}$ is always higher than the stress at point $\mathrm{L}_{1}$ for any time.

Increase in maximum deflection with time are also shown in Figures 26(b) and 27(b). As mentioned in [24], the deflection requirement of deflection limits of a railway bridge for serviceability limit state under live load plus dynamic load allowance shall not be greater than $1 / 640$ of the span. It is obvious that deflection in this analysis is not a safety issue for Bridge 62. In contrast, for the Bridge 44 , the time ( 160 years) of its deflection reaching limit is happening before the bridge steel yield as corrosion ( $\sim 250$ years $)$. 
These results revealed that failure due to material loss (Corrosion) determined merely by outer flange fibre stress of girder is not enough. The stress at different point and deflection also needs to be considered dependent on the section of the girder.

\subsection{Failure due to combined action of corrosion and cracking}

If we are to assess damage in Australian Rail bridges, it is important to establish the crack growth tools developed can be used to accurately predict crack growth, in a representative structural member under a complex load time spectra.

Since the life of the corroded steel bridge is a strong function of the corrosion rate, in this paper, the interaction of combined corrosion and crack growth has been considered. To avoid a computationally intensive process of traditional stress intensity factors calculation method, an alternative and simple approach has been used in this paper to get stress intensity factors. It is assumed that the stress intensity factor for the crack in corroded steel beam $K_{I}$ can be expressed as: per Eq. (6):

$$
K_{I}(a, c)=F_{\sigma} K_{I(\text { Original })}\left(a^{*}, c^{*}\right)
$$

Here, $F_{\sigma}$ is the geometry evolution factor. The stress intensity factor $K_{I(\text { Original })}\left(a^{*}, c^{*}\right)$ is obtained by using the method provided by $[11,14]$. The $(\mathrm{a}, \mathrm{c})$ and $\left(\mathrm{a}^{*}, \mathrm{c}^{*}\right)$ are the crack size of without and with corrosion and its dependency can be expressed as, see Figure 25.

$$
\begin{aligned}
& a^{*}=a-\xi N \\
& c^{*}=c \sqrt{1-(\xi N / a)^{2}}
\end{aligned}
$$

The geometry evolution factor $F_{\sigma}$ is determined with the following equation:

$$
F_{\sigma}=\frac{2 y^{*}-t^{*} I}{2 y-t I^{*}}
$$

Having determined a solution for the SIF (Stress Intensity Factors), the next step is to apply this to the integration of crack growth over the remaining life of the bridge.

Having the results from previous approach [23] thus shown that:

i) It appears that, in general, effect of the environment initiates corrosion damage and grow cracks during periods of inactivity as oppose to during transit of a train;

ii) that the growth of both small and long cracks can be unified by expressing $\mathrm{da} / \mathrm{dN}$ as a function of $\Delta \mathrm{K}-\Delta \mathrm{K}_{\mathrm{thr}}$, as first suggested by Hartman and Schijve [15], rather than $\Delta \mathrm{K}$.

The crack growth model used in this paper is based on a variant of the Hartman-Schijve [15] concept, i.e. that $d a / d N$ should be dependent on the amount by which $\Delta K$ exceeds the fatigue 
threshold $\Delta K_{t h r}$ of the material under the associated test environment, to investigate a variant of the original Hartman-Schijve equation, viz:

$$
d a / d N=D\left[\left(\Delta K-\Delta K_{t h r}\right) / \sqrt{ }\left(1-K_{\max } / \mathrm{A}\right)\right]^{\eta}
$$

where is a constant that is generally approximately 2 . Corrosion rate data must be collected over an extended period to give an accurate value and the process cannot be hurried: this is the critical time path in the data collection process. The load data, the frequency of loading and how the load is applied must be gathered over a representative period to give reliable results. A pilot sample of load data and 18 months of the loss-of-material-to-corrosion data was collected.

Analysis of the measured steady state corrosion data gave a state corrosion rate of $\xi=0.024$ $\mathrm{mm}$ per year for Bridge 62 and $\xi=0.053 \mathrm{~mm}$ per year for Bridge 44 . The crack growth characteristics are similar to the various (representative) bridge steels analysed in [23], viz. $D$ $=1.5 \times 10^{-10}, \mathrm{~A}=140 \mathrm{MPa}$ and $\eta=2$. ASTM E647-13a and [15] questions the existence of a fatigue threshold for naturally occurring cracks. The value of the fatigue threshold, $\Delta \mathrm{K}_{\mathrm{thr}}=$ $0.1 \mathrm{MPa} \sqrt{\mathrm{m}}$, was taken to be that determined in [23] for the corroded bridge steel tests on samples taken from Kilmore East Bridge. As such equation (6) essentially reduces to the strain energy density crack growth equation presented in $[17,18]$.

The next stage of this study was to use the finite element model to compute crack growth. The loading applied to model was based on the worse case when an ore train (Included one $G$ Class locomotive and 20 fully loaded wagons) go over the bridge. The G Class locomotive has the following specifications: Total weight $=128$ tonnes, axle loading $=21.3$ tonnes, wheel base $=3810 \mathrm{~mm}$, axle spacing $=1905 \mathrm{~mm}$ and leading wheel leading bogie to leading wheel trailing bogie $=12622 \mathrm{~mm}$. Due to symmetry considerations, only quarter of the wheel was modelled. The resultant mesh, which was created using software program FEMAP [25], had 18146 twenty-one-noded elements and 91590 nodes (with 274770 degrees of freedom), see Figures 28 and 29. The stresses at critical region are in good agreement with the results from field strain gauges measurement [26].

The Equations 2 to 6 consequently used to do crack growth analysis in this paper. Here, it is allowing for changes in the section thickness as the section corrodes.

The resultant crack growth results are given in Figures 30. In this analysis, if the crack growth in a year is less than $0.024 \mathrm{~mm}$, it is assumed that the crack has been "eaten" by corrosion. In this analysis, the initiating (inherent) crack was taken from [23], which tested a section from a condemned and badly corroded steel bridge, to be a $0.05 \mathrm{~mm}$ deep semicircular initial crack. The section thickness is reduced accordingly and the stresses increased. This analysis yielded a life to failure of approximately 116 years. There is a difference of $\sim 28.9 \%$ in the computed fatigue life between the no corrosion and with corrosion effect case. Since the life of the bridge is a strong function of the size of the initiating defect, the analysis was repeated for a range of initial crack sizes and the resulting lives are shown in Figures 3031. The percentage difference between the case of no corrosion and with corrosion effect reduced as the size of initial crack increased.

\section{CONCLUSIONS}

This data presented in this paper supports the ASHTO recommended metal loss model. The paper also presents a methodology for computing the growth of cracks that arise due to 
natural corrosion in bridge steels. It is shown that the durability of bridge structures becomes a competition between crack growth during operational loading and the loss of material due to corrosion.

From the analysis provided in this paper, it is revealed that failure assessment of steel bridges needs to account for the interaction between fatigue crack growth and the increase in stress, that arises from the corrosion process, due to the reduction in the section thickness. The methodology described in this paper is ideal for use in steel bridges. It allows accurate results to be obtained without the need to explicitly model a crack. However, it is still necessary to model the uncracked structure.

\section{REFERENCES}

1. AREMA Bridge Inspection Handbook: Railway Track \& Structures, USA 2016.

2. R. Akid, T. Richardson, Corrosion Fatigue. In Shreir's Corrosion. (Vol. 2, pp. 928-953), 2010.

3. M. R. Ayatollahi, S. M. J. Razavi, H. R. Chamani, A numerical study on the effect of symmetric crack flank holes on fatigue life extension of a SENT specimen. Fatigue \& Fracture of Engineering Materials \& Structures, 37, 10, pp. 1153-1164 (2014).

4. M. R. Ayatollahi, S. M. J. Razavi, M. Y. Yahya MY, Mixed mode fatigue crack initiation and growth in a CT specimen repaired by stop hole technique. Engineering Fracture Mechanics, Vol. 145, pp. 115-127 (2015).

5. S. M. J. Razavia, M. R. Ayatollahia, C. Sommitsch, C. Moser, Retardation of fatigue crack growth in high strength steel S690 using a modified stop-hole technique, Engineering Fracture Mechanics, Vol. 169, pp. 226-237 (2017).

6. X. L. Zhao, L. Zhang, State-of-the-art review on FRP strengthened steel structures, Engineering Structures, 29, 8, pp. 1808-1823, 2007.

7. K. Ali, RRK. Singh, XL. Zhao, R. Jones and A. J. McMillan., Composite repairs to bridge steels demystified, Journal of Composite Structures, 2016, Volume 169, 1, 2017, pp. 180189.

8. D. N. Adasooriya, Fatigue reliability assessment of ageing railway truss bridges: Rationality of probabilistic stress-life approach, Case Studies in Structural Engineering 6 (2016) 1-10.

9. N. D. Adasooriya and S. C. Siriwardane, Remaining fatigue life estimation of corroded bridge members, Fatigue. Fract. Engng. Mater. Struct. 37 (2014) 603-622.

10. W.T.M.S.M. Wanninayake, W.M.P.R. Wasala, C.S. Bandara, Life evaluation of critical members of steel bridges located in different atmospheres, Proceedings of the $6^{\text {th }}$ International Conference on Structural Engineering and Construction Management, Kondy, Sri Lonko, Dec 11-13, 2015.

11. T. Q. Zhou, T.H.T. Chan, Y. Hua, Fatigue Damage Analysis on Crack Growth and Fatigue Life of Welded Bridge Members with Initial Crack, Key Engineering Materials 324-325 (2006) 251-254.

12. A. Carpinteri, C. Ronchei, S. Vantadori, Stress intensity factors and fatigue growth for surface cracks in notched shells and round bars: two decades of research work. Fatigue and Fracture of Engineering Materials and Structures 36, 11 (2013), pp. 1164-1177.

13. A. Carpinteri, C. Ronchci, D. Scorza, S. Vantadori, Fracture mechanics based approach to fatigue analysis of welded joints. Engineering Failure Analysis 49 (2015), pp. 67-78.

14. D. Peng, C. Wallbrink, R. Jones, Stress intensity factor solutions for finite body with quarter-elliptical flaws emanating from a notch. Eng. Fract. Mech. 72 (2005) 1329-1343. 
15. R. Jones, Fatigue crack growth and damage tolerance, Fatigue. Fract. Engng. Mater. Struct. 37 (2014) 463-483.

16. R. Jones, D. Peng, S. Pitt, C. Wallbrink, Weight Functions, CTOD, and Related Solutions for Cracks at Notches, Engineering Failure Analysis 11 (2004) 79-36.

17. F. Berto, A. Campagnolo, F. Chebat, M. Cincera, M. Santini, Fatigue strength of steel rollers with failure occurring at the weld root based on the local strain energy values: modelling and fatigue assessment, International Journal of Fatigue, 82 (2016) 643-657.

18. F. Berto, P. Lazzarin, Recent developments in brittle and quasi-brittle failure assessment of engineering materials by means of local approaches, Materials Science and Engineering R, 75 (2014) 1-48.

19. K. L. Fishman, J. L. Withiam, LRFD Metal Loss and Service-Life Strength Reduction Factors for Metal-Reinforced Systems, NCHRP 675, Transportation Research Board, Washington, DC, 2011.

20. AASHTO, LRFD Bridge Design Specifications, 4th Ed. With Interims, American Association of State Highway and Transportation Officials, Washington, D.C. 2009.

21. ISO 9224: Corrosion of metals and alloys - Corrosivity of atmospheres - Guiding values for the corrosivity categories. Published in Switzerland, 2012.

22. P. Albrecht, Jr T.T. Hall, Atmospheric Corrosion Resistance of Structural Steels, Journal Of Materials In Civil Engineering 15 (2003) 1-24.

23. K. Ali, D. Peng, R. Jones, R. R. K. Singh, X. L. Zhao, A. J. McMillan, F. Berto, Crack growth in a naturally corroded bridge steel, Fatigue \& Fracture of Engineering Materials \& Structures, 40, 7 (2017), pp. 1117-1122.

24. Bridge Design Australian Standard, AS 5100.2-2004.

25. FEMAP - Finite Element Modelling and Post Processing, Version 11.1.2, Structural Dynamics Research Corporation, Pennsylvania; 2015.

26. D. Peng, K. Cairns, Bridge 62 near Kilmore East Strain Gauge Data Analysis, Rail CRC report, Monash University, March, 2012.

27. L. F. Gillemot, Brittle fracture of welded materials. In: Commonwealth Welding Conference; 1965, C.7. 353-358.

28. L. F. Gillemot, E. Czoboly, I. Havas, Fracture mechanics applications of absorbed specific fracture energy: notch and unnotched specimens, Theor Appl Fract Mech, 1985; 4: $39-45$.

29. G. C. Sih, Strain-energy-density factor applied to mixed mode crack problems, Int J Fract $1974 ; 10: 305-32$.

30. G. C. Sih, Mechanics of Fracture Initiation and Propagation, Dordrecht: Kluwer Academic Publisher; 1991.

31. E. E. Gdoutos, Fracture Mechanics Criteria and Applications, Dodrecht: Kluwer Academic Publishers; 1990.

32. R. Badaliance, Application of strain energy density factor to fatigue crack growth analysis, Engineering Fracture Mechanics, 1980, 3, pp. 657-666.

33. Hart-Smith LJ., Adhesively bonded double lap joints, NASA Langley Research Center Report NASA CR-112235, January 1973.

34. Hart-Smith LJ., Adhesive bonded scarf and lap joints, NASA Langley Research Center Report NASA CR-112237, January 1973.

35. CMH-17-3G, Composite Materials Handbook, Volume 3: Polymer Matrix Composites Materials Useage, Design and Analysis, Published by SAE International, March 2012.

36. Jones R., Chiu WK. and Paul J., Designing for damage tolerant bonded joints, Composite Structures, 25, 201-207, 1993.

37. Chiu WK., Rees D., P. Chalkley and Jones R., Designing for damage tolerant repairs, Journal of Composite Structures, 28, 1, 19-38, 1994. 
38. Jones R., Sawyer J. and Chiu WK., Studies in the matrix dominated failures of composite joints, Journal of Composite Structures, 44, 1-16, 1999.

39. Jones R., Chapter 9, Numerical Analysis and Design, in Advances in the Bonded Composite Repair of Metallic Aircraft Structure, Edited by A. Baker, L. R. F. Rose and Jones R., Elsevier Applied Science Publishers, 2002. ISBN 0-08-042699.

40. Jones R., Kotousov A. and Marshall IH., Adhesively bonded joints under cyclic load spectra, Fatigue and Fracture of Engineering Materials and Structures, 25, 1-13, 2002.

41. Teodosiadis, R., Plastic Analysis of Bonded Composite Lap Joints, Douglas Aircraft Company, IRAD Report No. DAC-67836, May 1969.

42. R. Jones, D. Tamboli, (2013) Implications of the lead crack philosophy and the role of short cracks in combat aircraft, Engineering Failure Analysis, 29.149-166.

43. Zonker HR., Bray GH., George K., Garratt MD., Use of ACR Method to Estimate Closure and Residual Stress Free Small Crack Growth Data, (2005) Journal of ASTM International, July/August 2005, Vol. 2, No. 7, Paper ID JAI12023, available online at www.astm.org

44. G. C. Sih, P. C. Paris, and G. R. Irwin, (1965) On cracks in rectilinearly anisotropic bodies, International Journal of Fracture Mechanics, 1, 3, pp.189-203.

45. R. Jones, A.J. Kinloch, W. Hu, Cyclic-fatigue crack growth in composite and adhesivelybonded structures: The FAA slow crack growth approach to certification and the problem of similitude, International Journal of Fatigue, 88, 2016, pp. 10-18. 


\section{APPENDIX: STRAIN ENERGY DENSITY AND FATIGUE CRACK GROWTH}

Strain energy density has long been used as a failure criteria for materials exhibiting both ductile and brittle behaviour [17, 18, 27-32]. It is also known to govern the failure of adhesively bonded joints and composite bonded scarf repairs to damaged composite structures [33 - 35]. In this context [33, 34] stated:

i) "The adhesive shear strain energy per unit bond area was the necessary and sufficient adhesive characteristic governing the potential bond shear strength."

ii) "The precise shape of the stress-strain curve appeared to be unimportant." This conclusion was supported by independent finite element studies [36-41].

When applied to crack growth there are currently two different variants. One approach expresses da/dN as a function of $\Delta \mathrm{S}$, where $\mathrm{S}=\mathrm{rW}$ and $\mathrm{r}$ is the distance from the crack tip, so that for Mode I growth $\mathrm{da} / \mathrm{dN}$ is expressed as a function of $\Delta\left(\mathrm{K}^{2}\right)$ [30-32]. The other approach expresses da/dN as a function of $\Delta \sqrt{ } \mathrm{S}$, or alternatively $\Delta \sqrt{\mathrm{W}}$, so that for Mode I growth $\mathrm{da} / \mathrm{dN}$ is expressed as a function of $\Delta \mathrm{K}$ [17-32]. Appendix X3 in the ASTM fatigue test standard E647-13a states:

"Fatigue cracks of relevance to many structural applications are often small or short for a significant fraction of the structural life. The growth rates of such cracks usually cannot be measured with the standard procedures described in the main body of Test Method E647, which emphasizes the use of large, traditional fracture mechanics specimen geometries."

With this in mind and noting that this paper focuses on the interaction of corrosion with small naturally occurring cracks let us consider the small and large $\mathrm{da} / \mathrm{dN}$ versus $\Delta \mathrm{K}$ data presented in [15] for crack growth in 7050-T7451 aluminium alloy, see Figure A1. The R = 0.33 data shown in Figure A1 is from [43]. The NASA $\mathrm{R}=0.4$ data is from the Nasgro data base. The initial crack lengths associated with the small crack data lie between approximately 3 microns up to 20 microns and the final crack length are of the order of $10 \mathrm{~mm}$.

Here we see that, as noted in $[15,42]$, the growth of small cracks essentially conforms to a Paris like equation and is largely $\mathrm{R}$ ratio independent. However, plotting the data as a function of $\Delta\left(\mathrm{K}^{2}\right)$ transforms Figure A1 to a near chaotic plot, see Figure A2. It also makes it appear that for a given value of the crack driving force, which in this instance is $\Delta\left(\mathrm{K}^{2}\right)$, tests performed at $\mathrm{R}=0.1$ are more severe than tests at $\mathrm{R}=0.7$ even though the later will have a greater $\mathrm{K}_{\max }$ value. The observation that for a given $\Delta \mathrm{W}$ tests at low $\mathrm{R}$ ratio's are more severe than tests at high R ratio's also follow from the crack growth data presented in [32]. This implication is counter intuitive. As such it would appear that it is best to relate da/dN to $\Delta \sqrt{ } \mathrm{W}$ $(\Delta \sqrt{ } \mathrm{S})$ rather than to $\Delta \mathrm{W}(\Delta \mathrm{S})$.

For pure Mode I and Mode II delamination growth in composites the energy release rate G is directly related to the strain energy density $\mathrm{W}$ [44]. Consequently this conclusion mirrors that given in [45] for Mode I and Mode II delamination growth where it is also noted that for delamination growth it is best to express $\mathrm{da} / \mathrm{dN}$ as a function of $\Delta \sqrt{ } \mathrm{G}$ rather than to $\Delta \mathrm{G}$ and that expressing da/dN as a function of $\Delta \mathrm{G}$ can lead to anomalous results. 


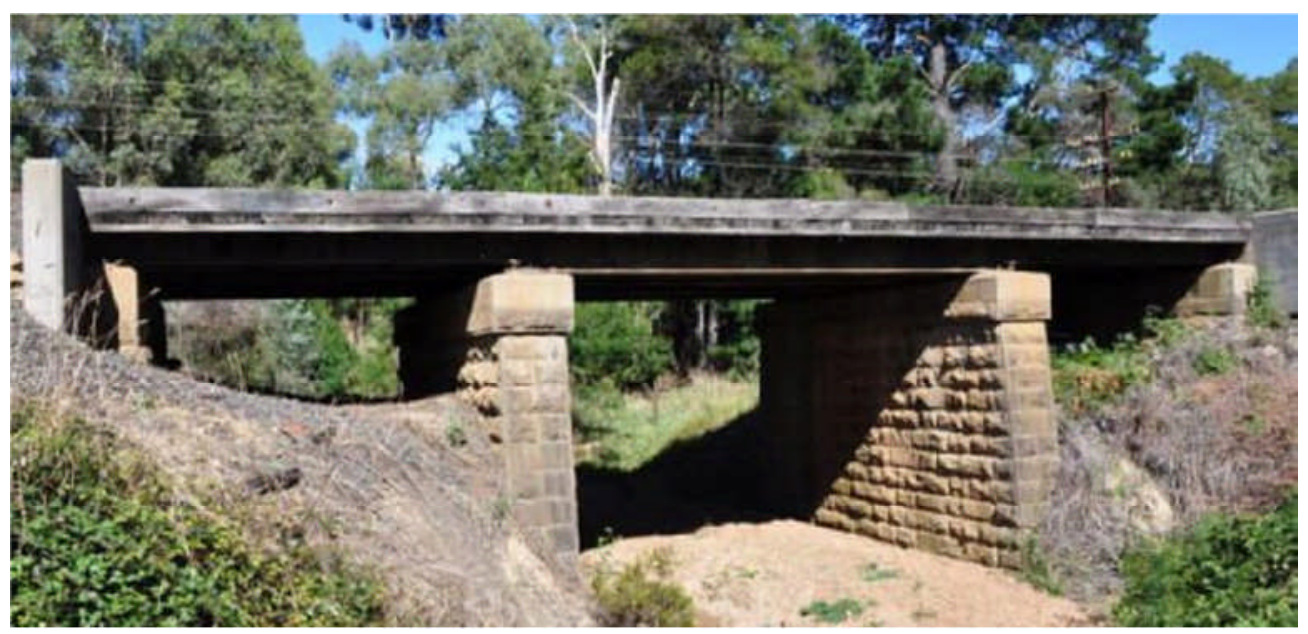

Figure 1 Bridge 62 near Kilmore East, Victoria

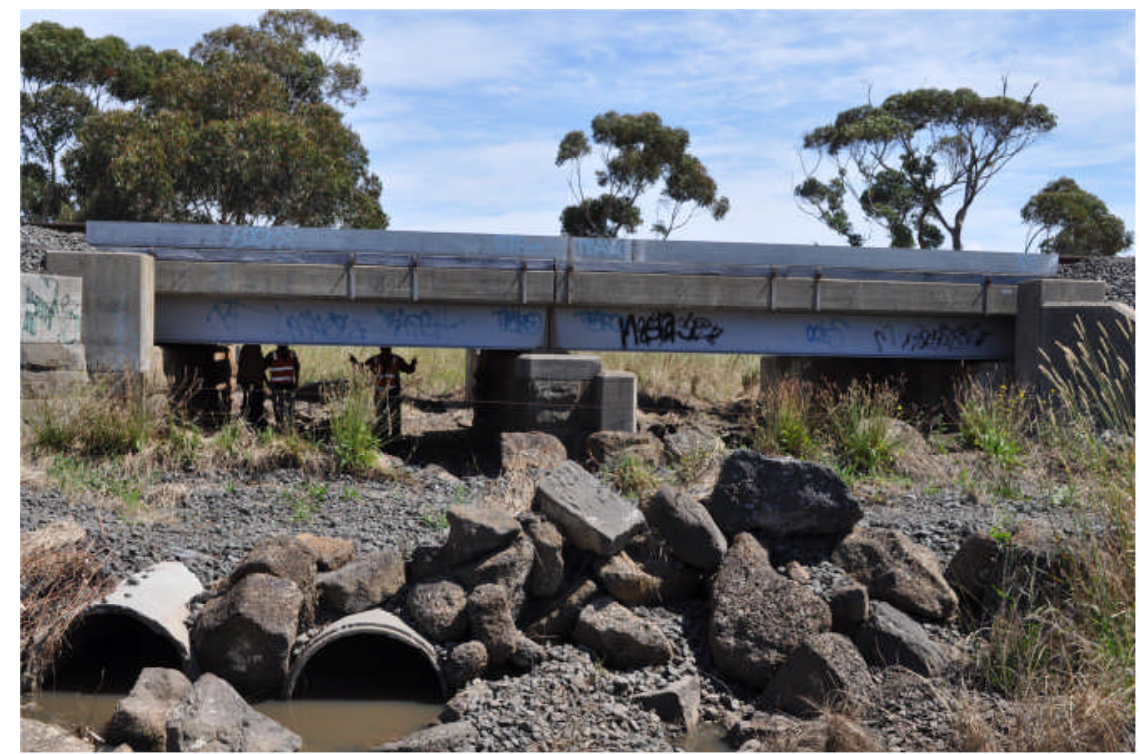

Figure 2 Bridge 44 near Little River, Victoria 


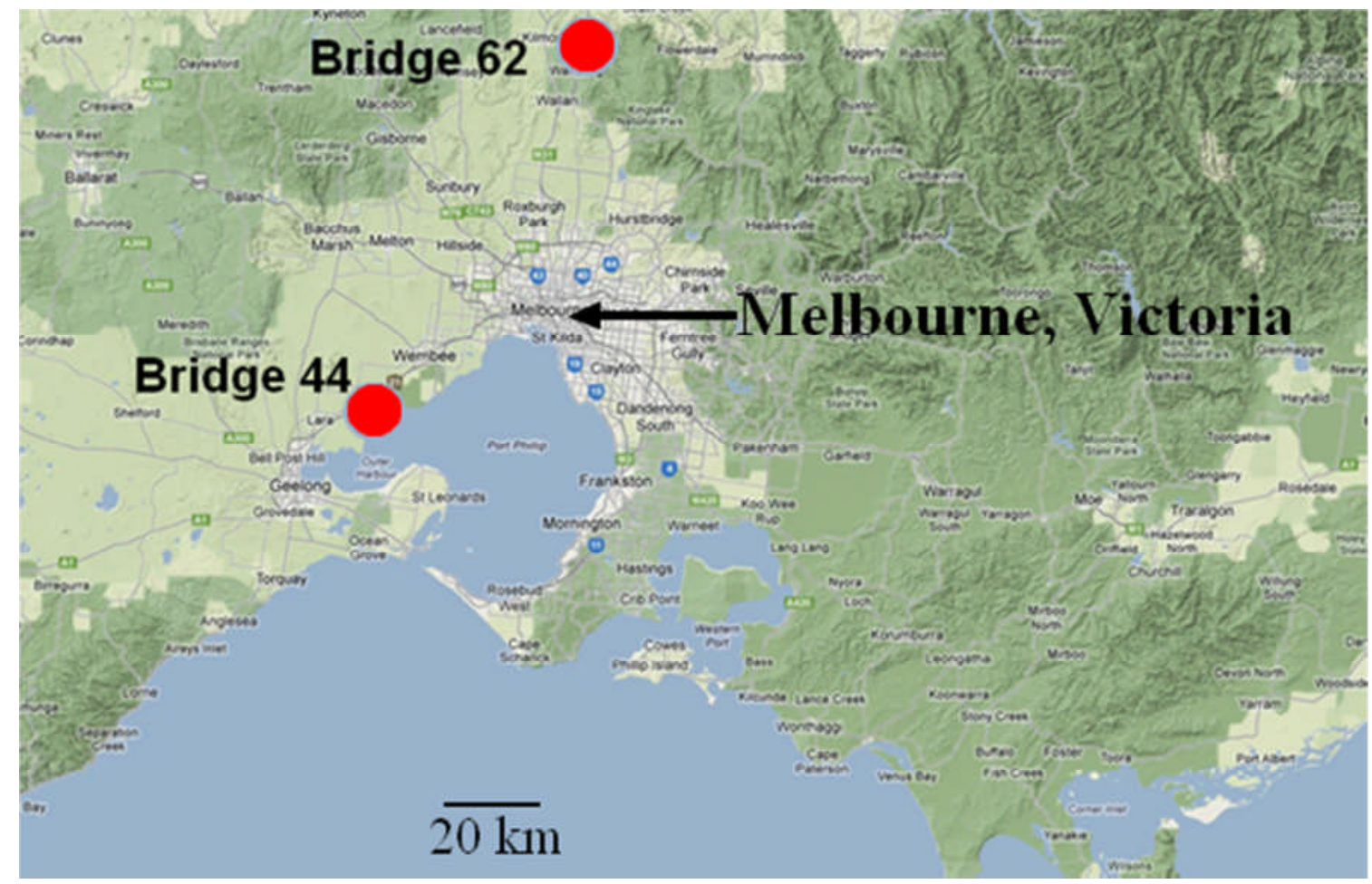

Figure 3 Locations of the V/Line Bridges 62 and 44, which lie outside of Melbourne, Victoria, Australia

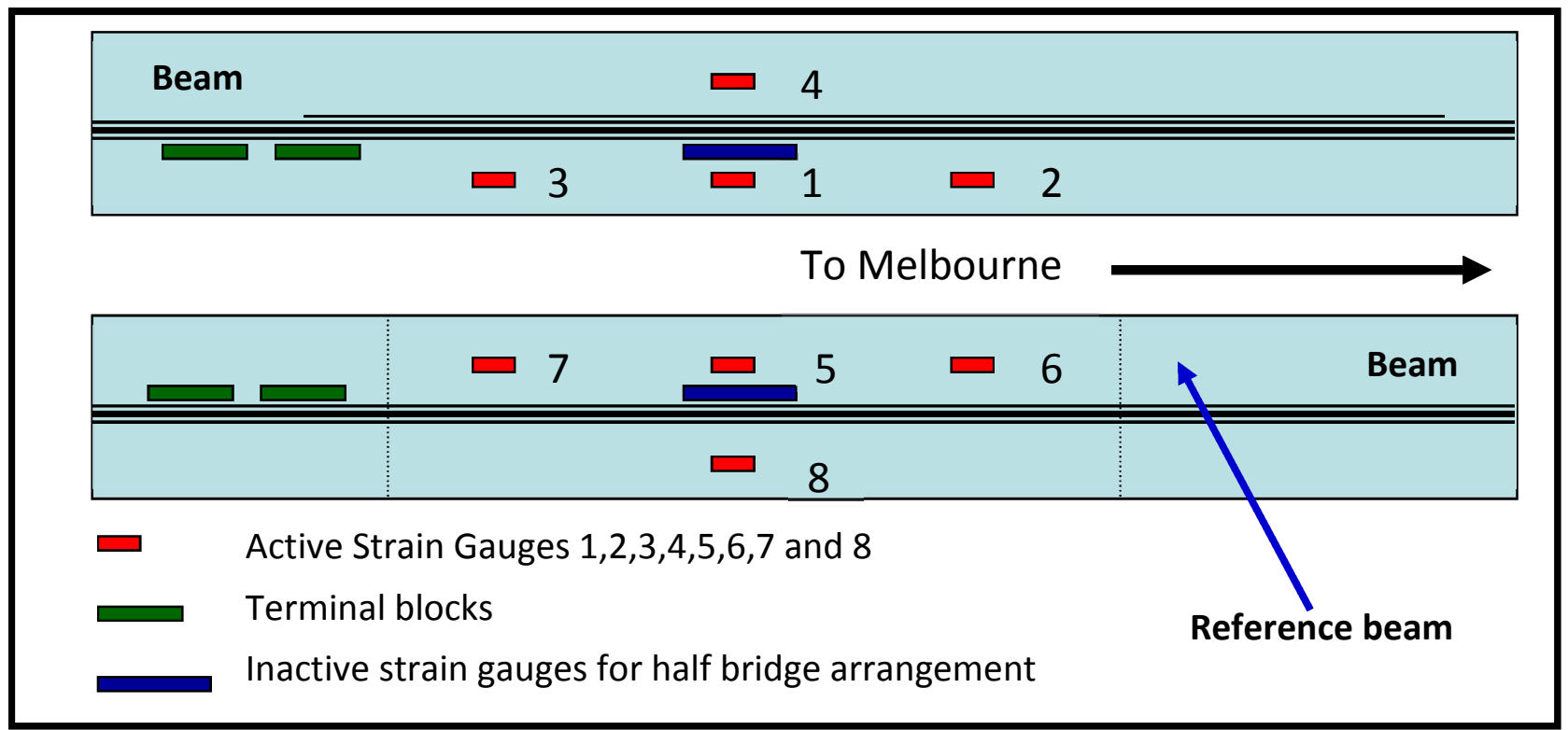

Figure 4 Location of strain gauges installed in bridge 62 


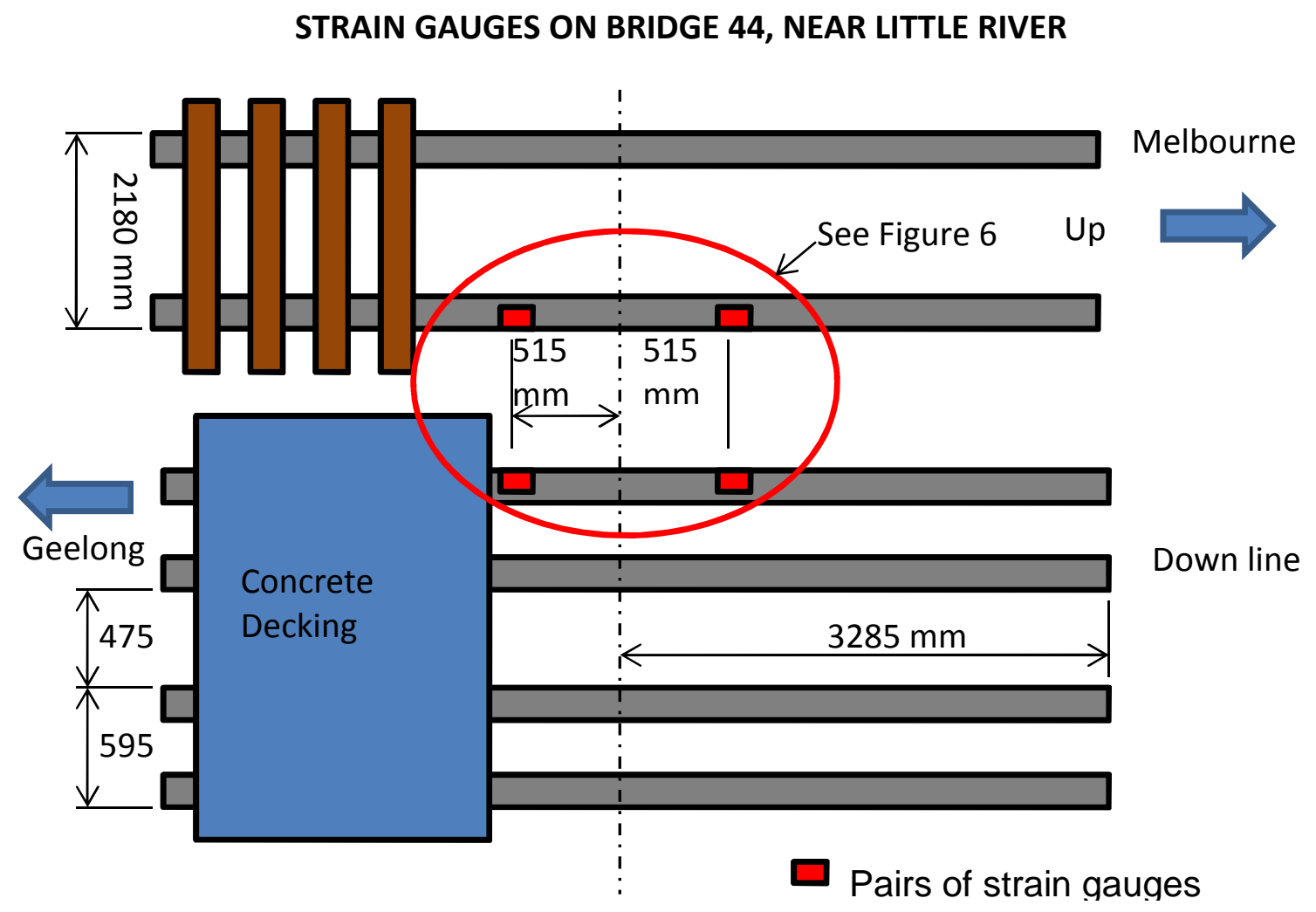

Figure 5 Strain gauges on bridge 44, near little river, all dimensions in $\mathrm{mm}$
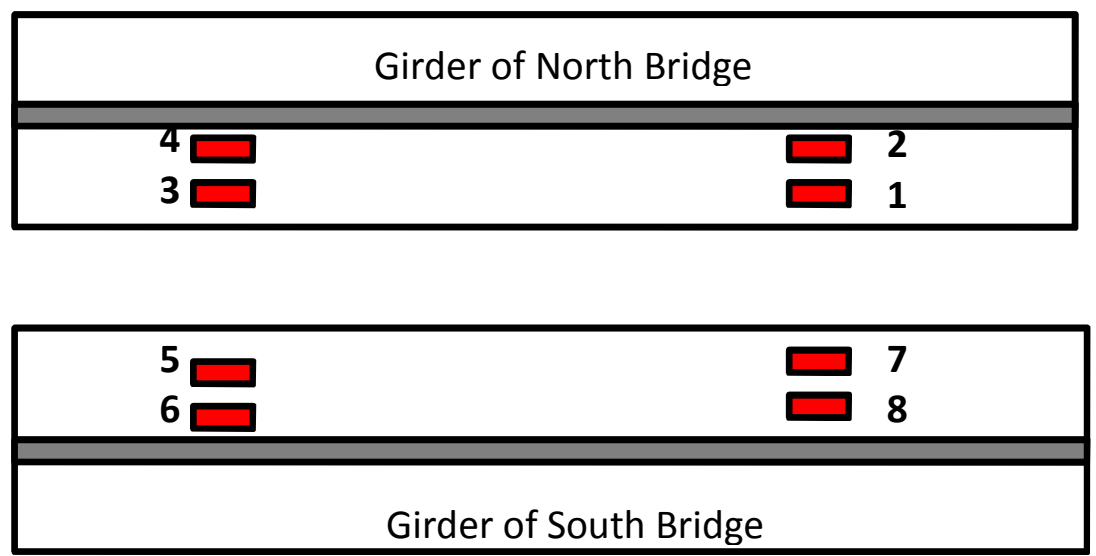

Figure 6 Detailed location of strain gauges installed on Bridge 44 


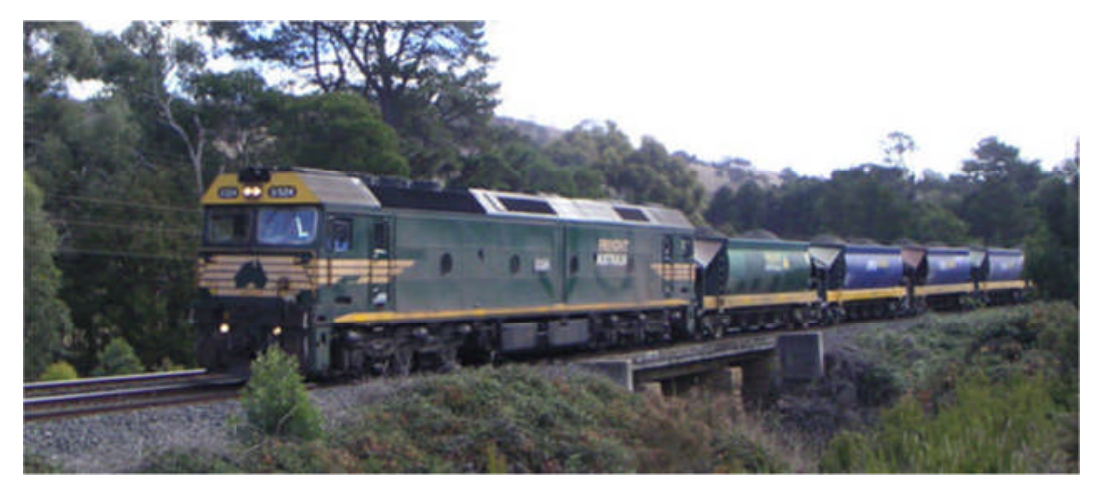

Figure 7 One G Class locomotive and 20 fully loaded wagons

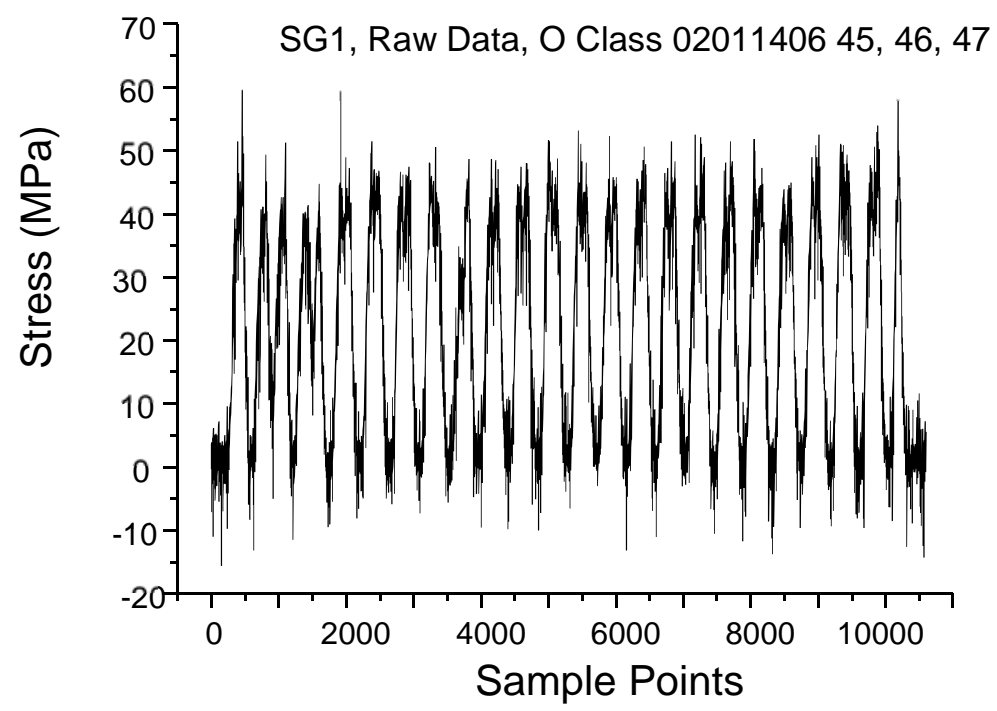

Figure 8 Load time history curve for the raw data of Ore Train at strain gauge 1 


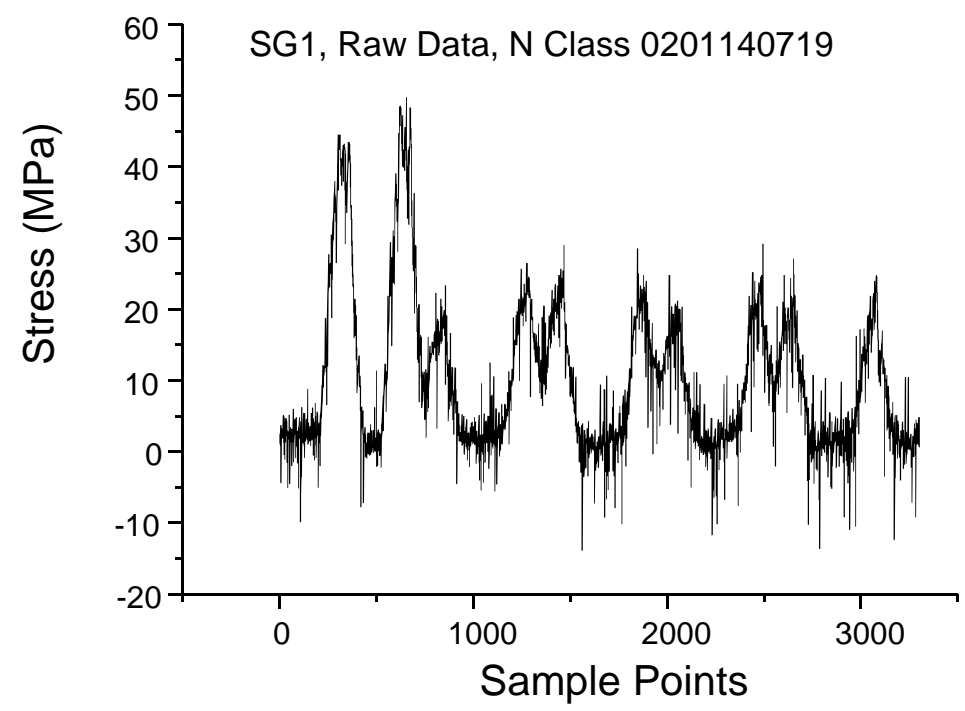

Figure 9 Load time history curve for the raw data of N Class Train at strain gauge 1 


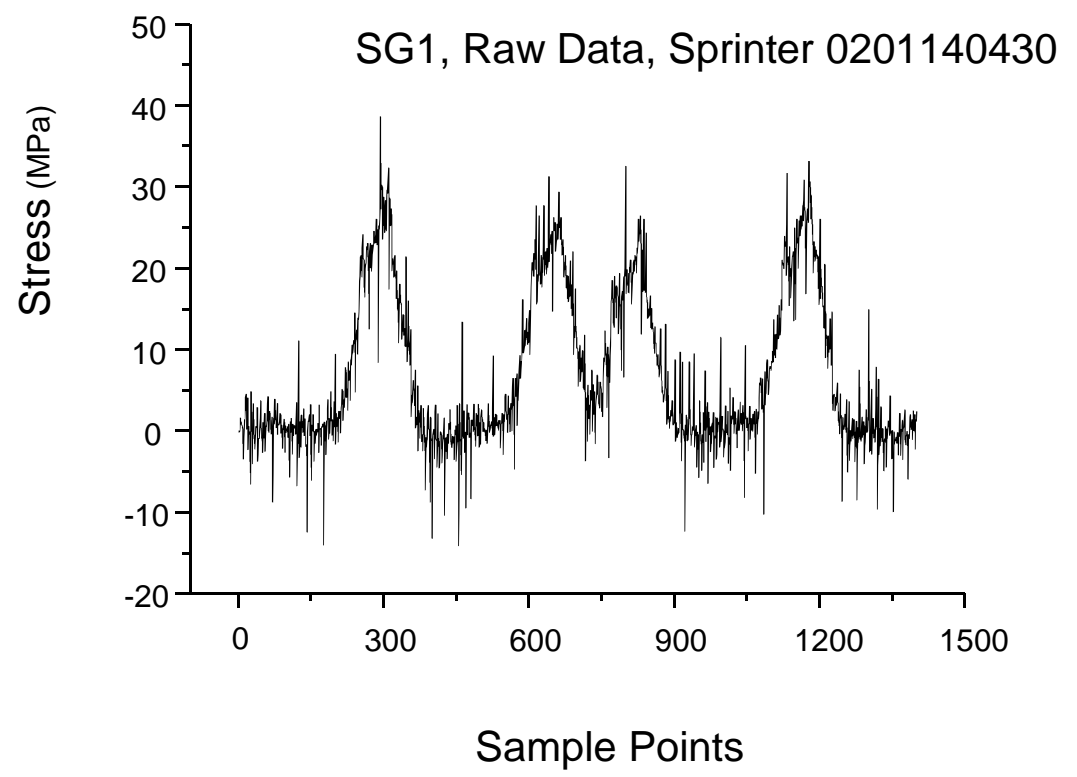

Figure 10 Load time history curve for the raw data of Sprinter 1 at strain gauge 1

Frequency $(\mathrm{Hz})$

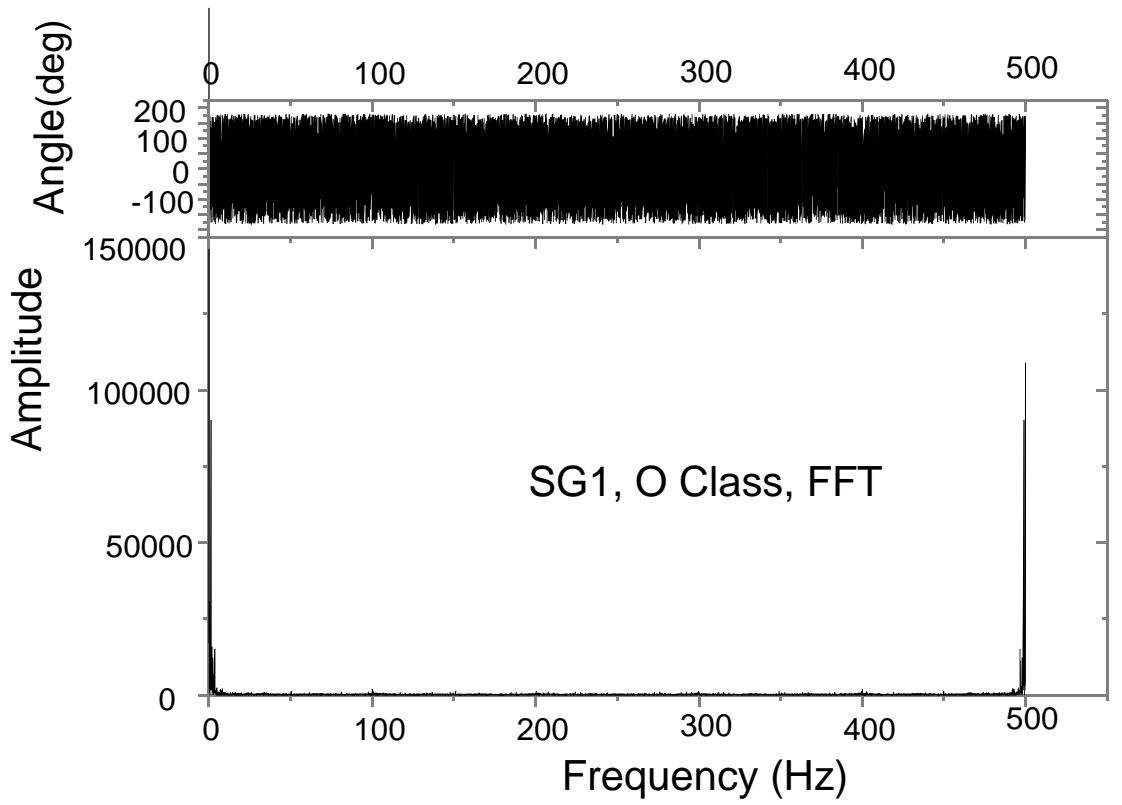

Figure 11 FFT of the raw data of the Ore Train at strain gauge 1 


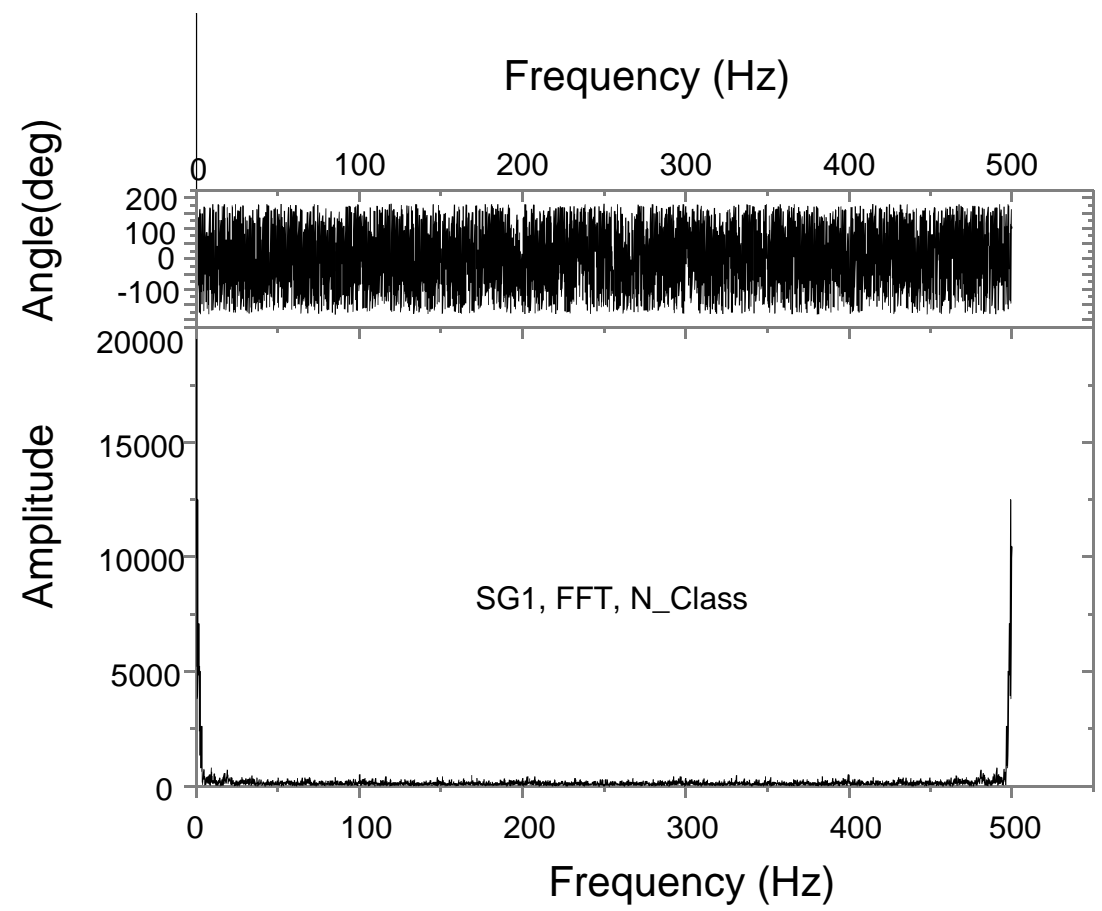

Figure 12 FFT of the raw data of the N Class at strain gauge 1

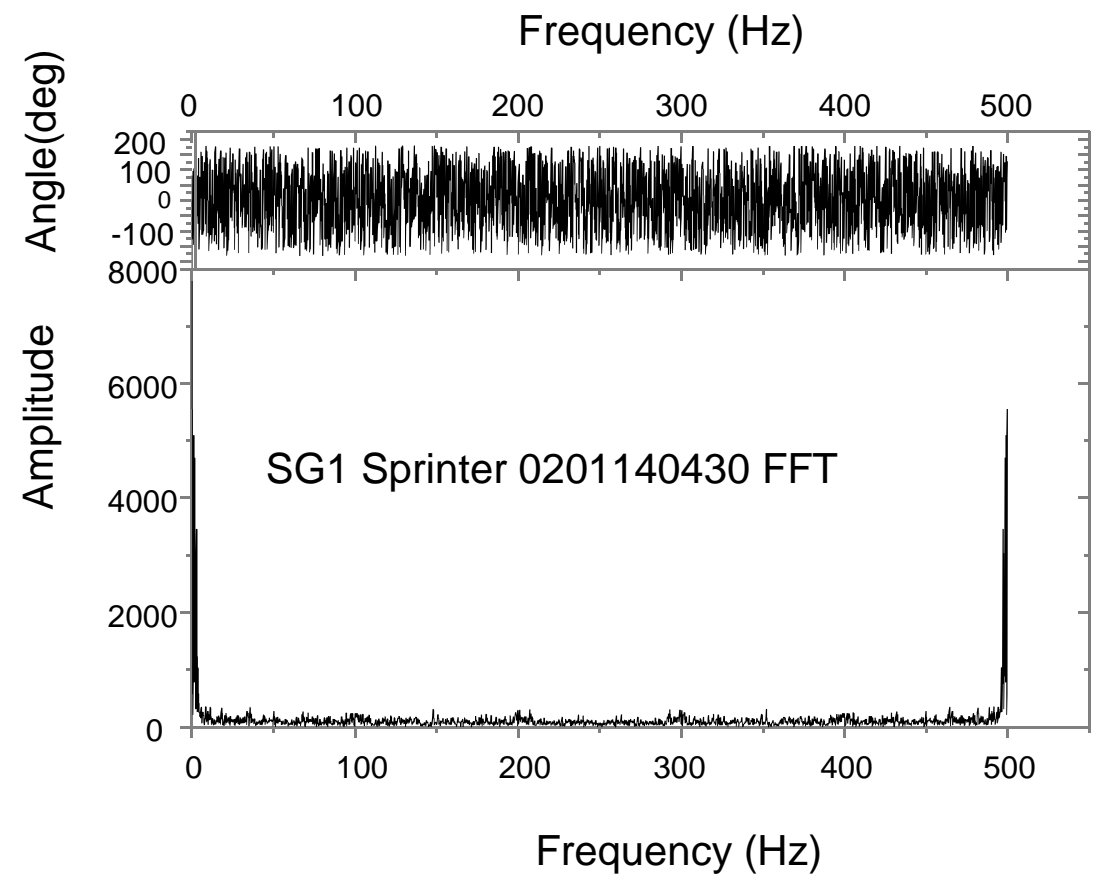

Figure 13 FFT of the raw data of the Sprinter 1 at strain gauge 1 


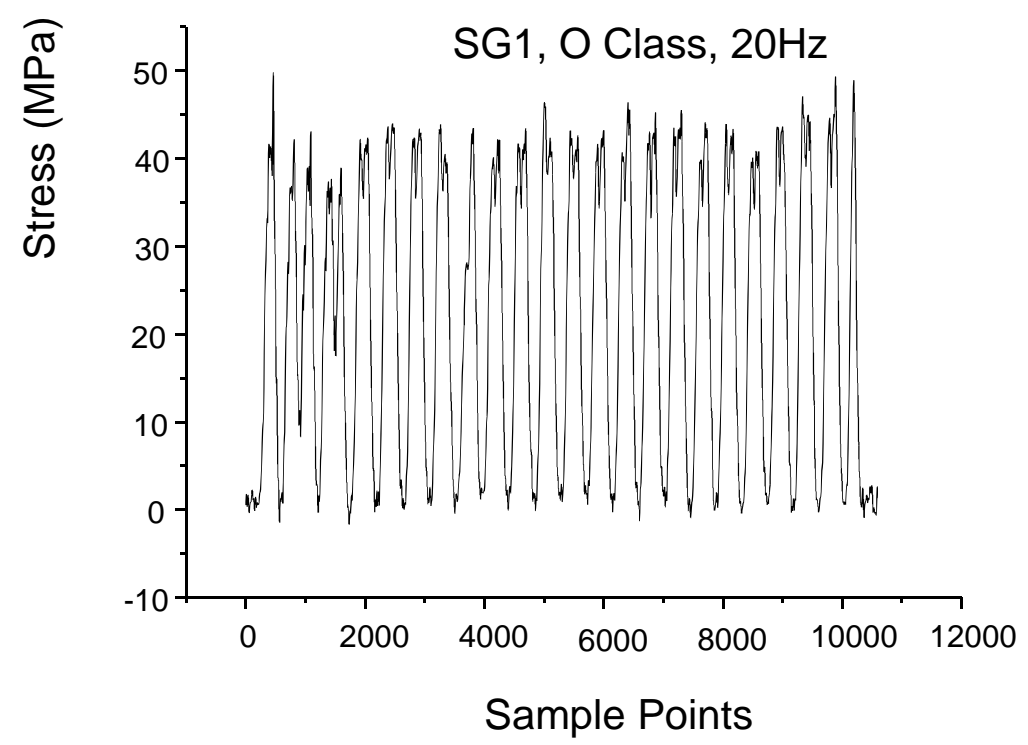

Figure 14 Load time history for the data of the Ore Train filtered at $20 \mathrm{~Hz}$

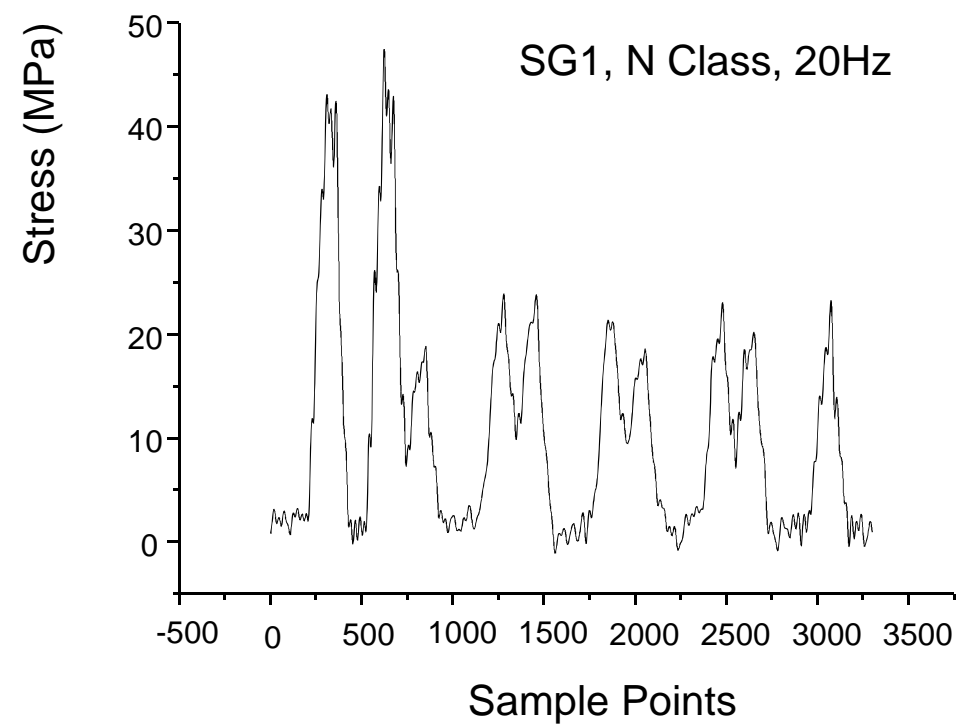

Figure 15 Load time history for the data of the N Class filtered at $20 \mathrm{~Hz}$ 


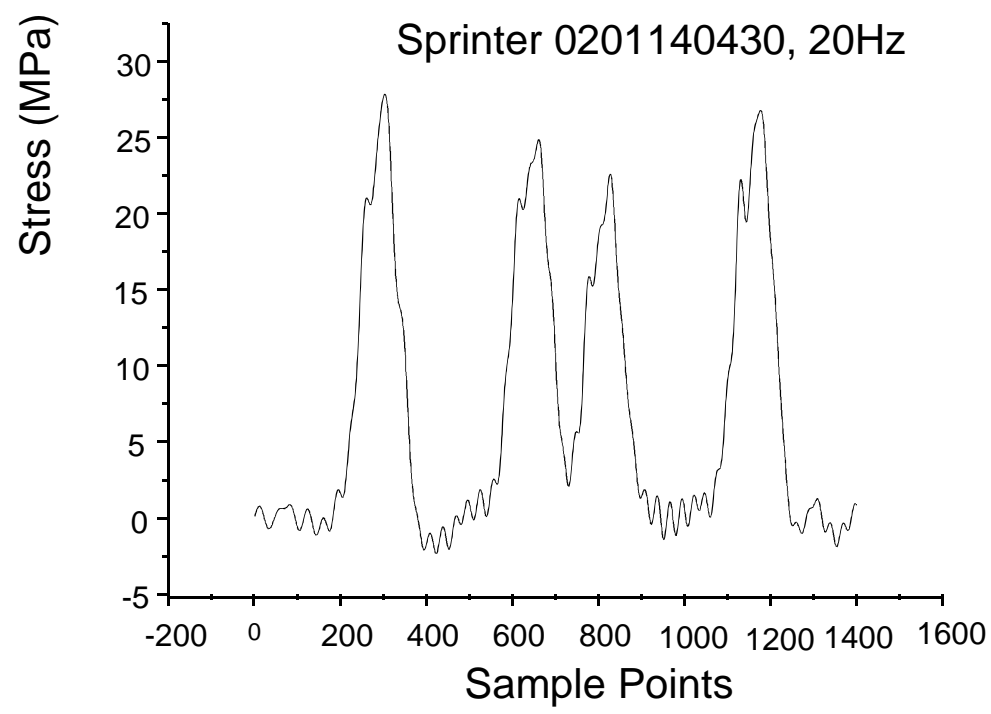

Figure 16 Load time history for the data of the Sprinter 1 filtered at $20 \mathrm{~Hz}$ 


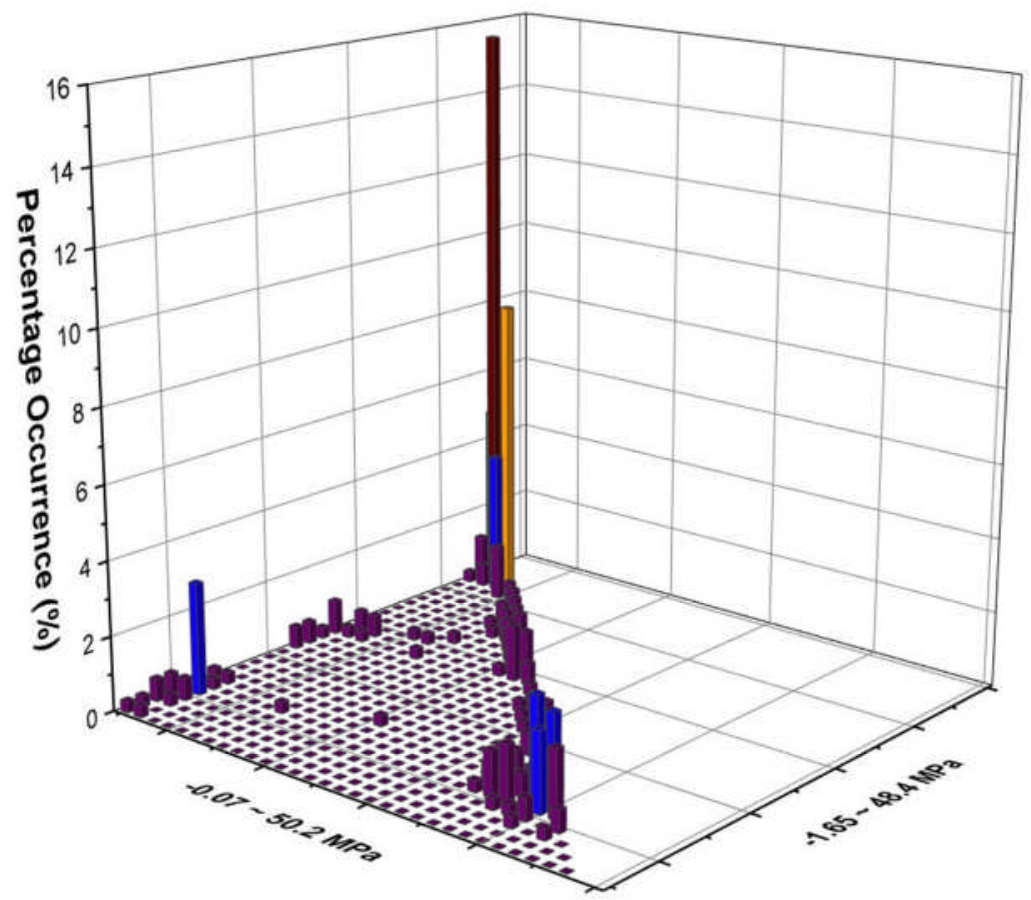

Figure 17 3D bar chart of the percentage occurrence distribution measured in Bridge 62 near Kilmore East

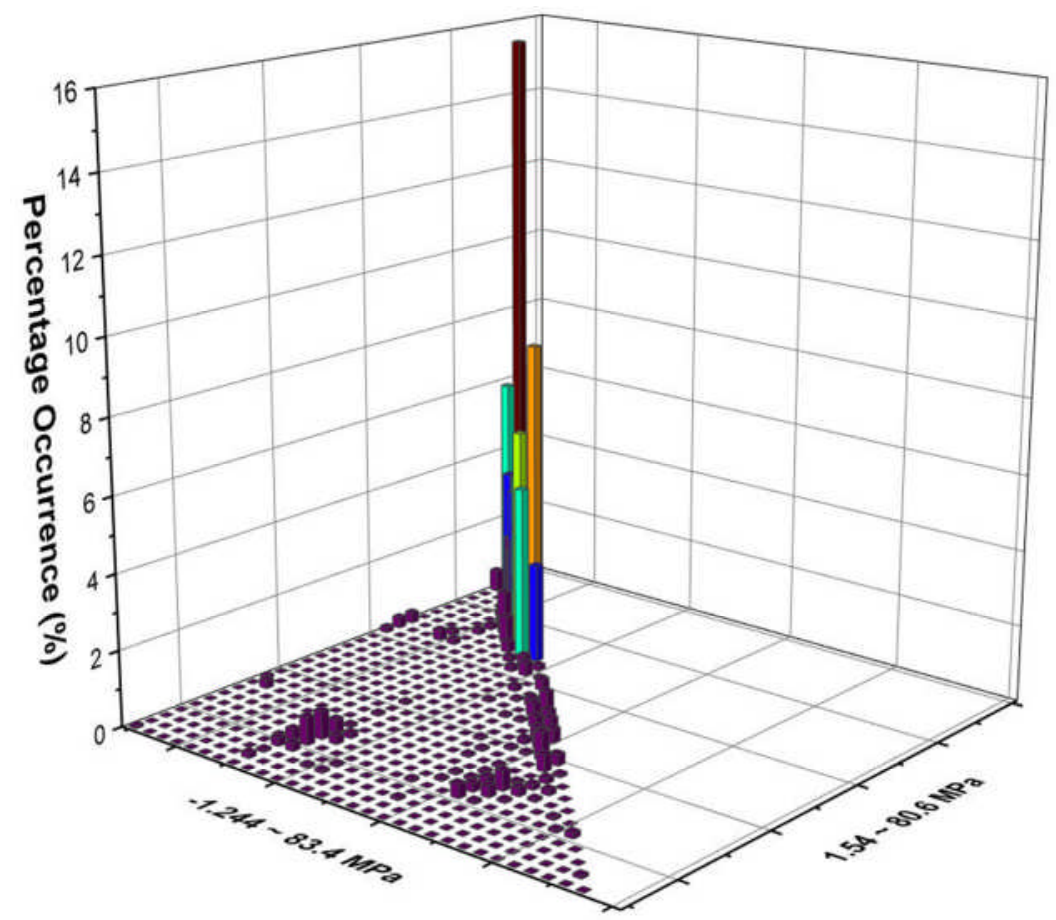

Figure 18 3D bar chart of the percentage occurrence distribution measured in Bridge 44 near Little River 


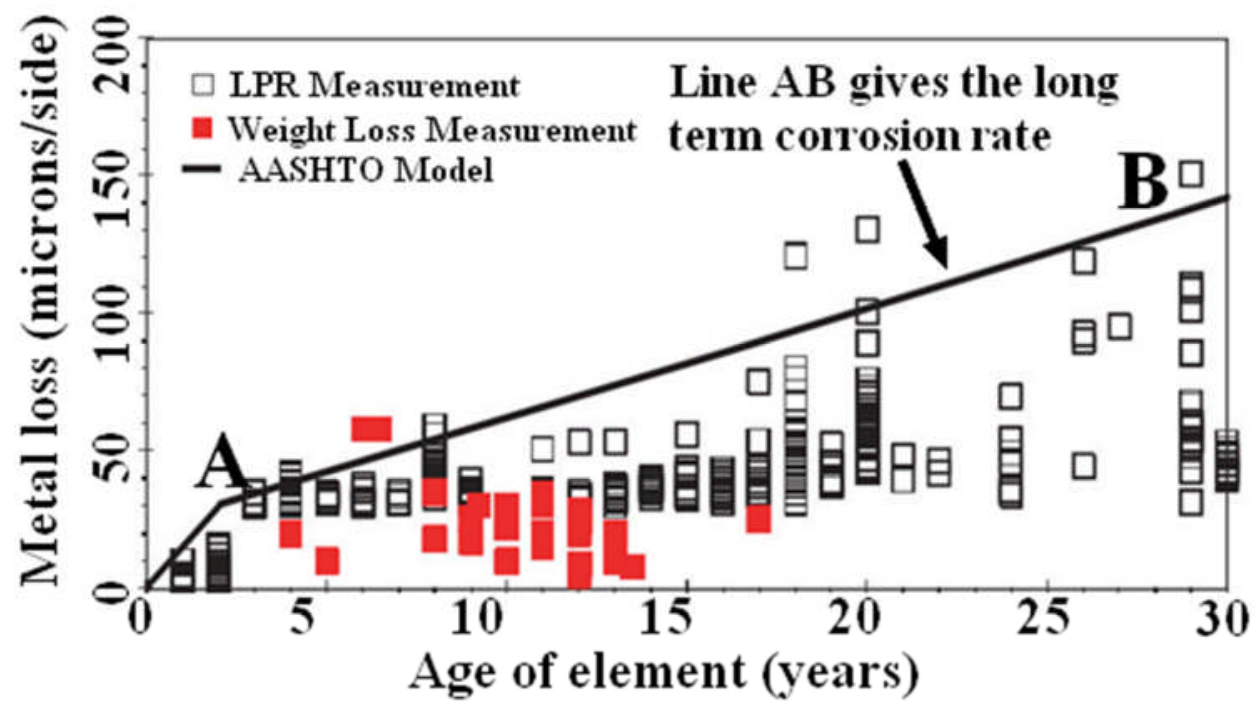

Figure 19 An example of the bi-linear metal loss versus time curve, from [19, 22]. 


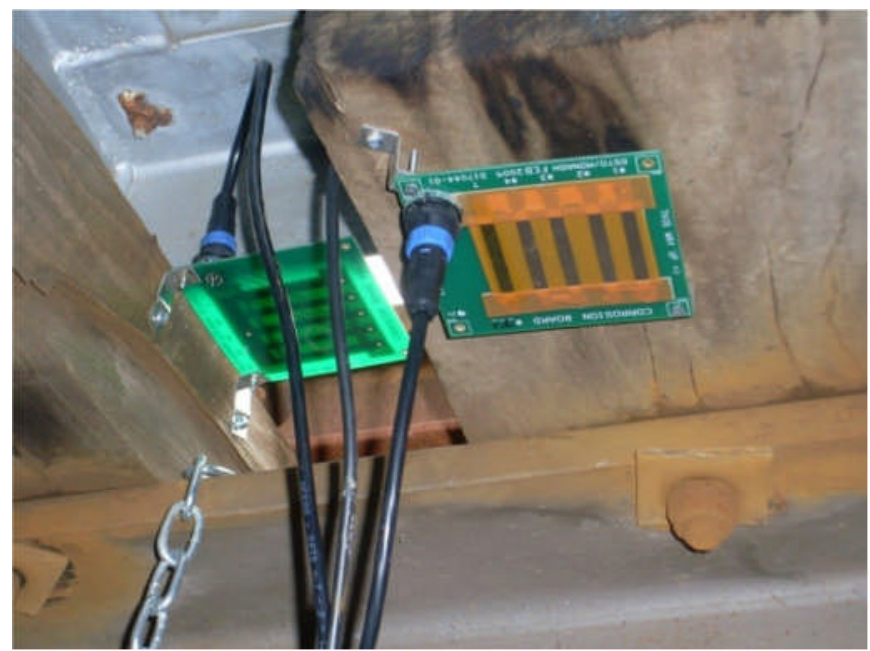

Figure 20DST Group Sensors Bridge 44
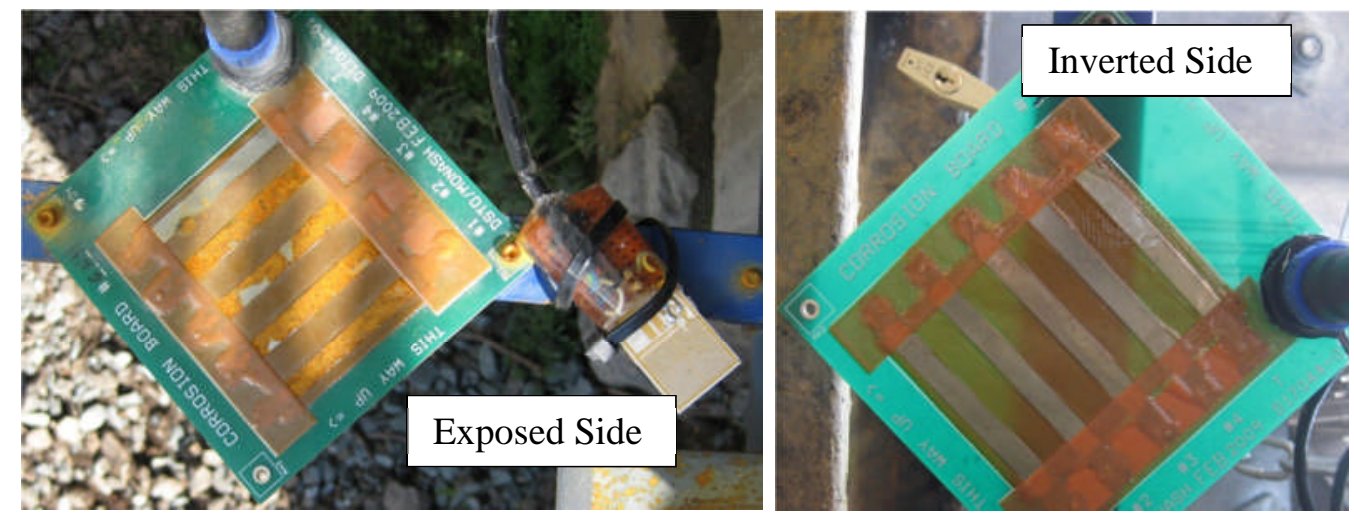

Figure 21 DST Group Sensors Bridge 62 


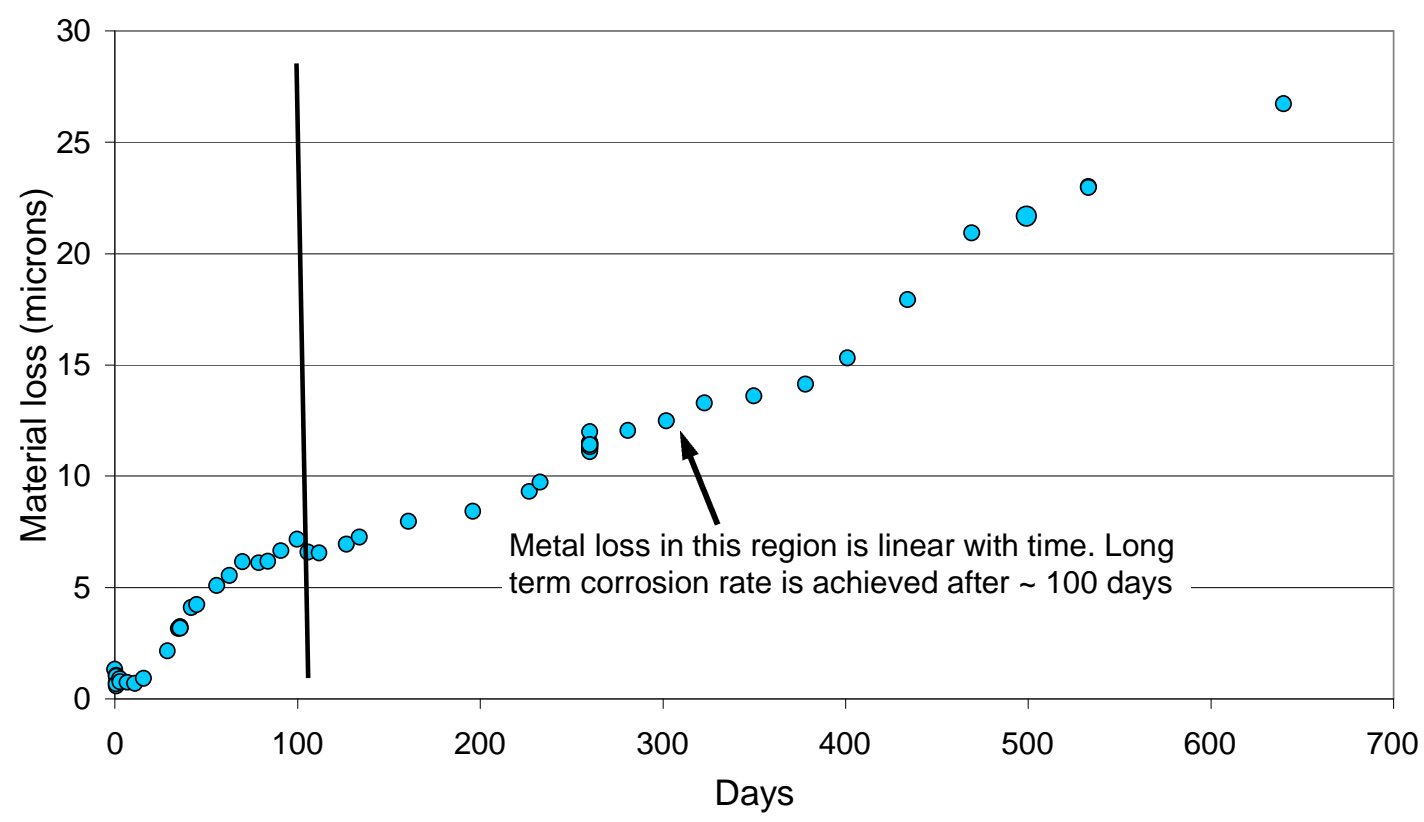

Figure 22 Measured thickness loss versus time at Clayton in Victoria.

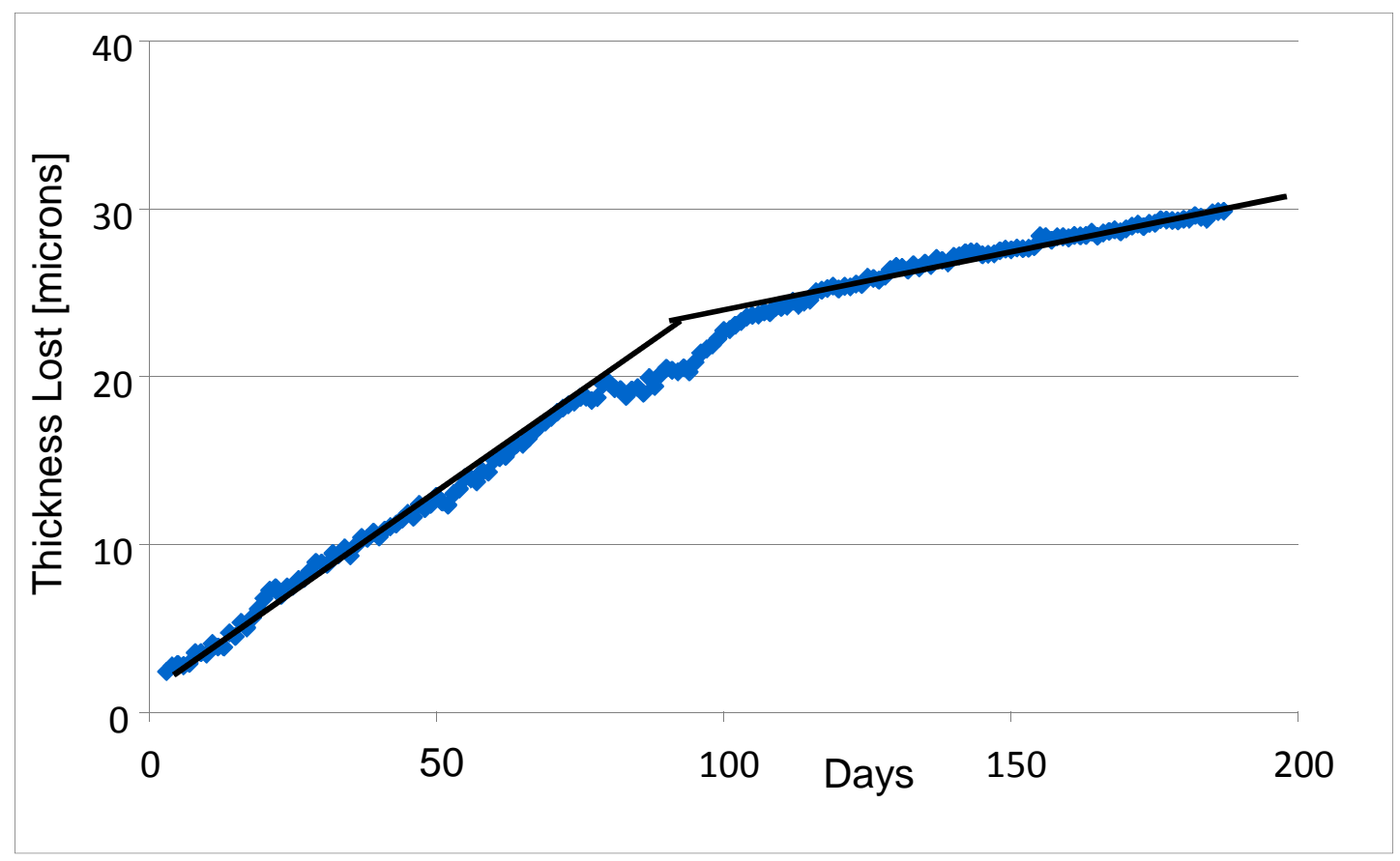

Figure 23 Measured thickness loss at Bridge 62 near 'Little River' on the coast between Melbourne and Geelong in Victoria 


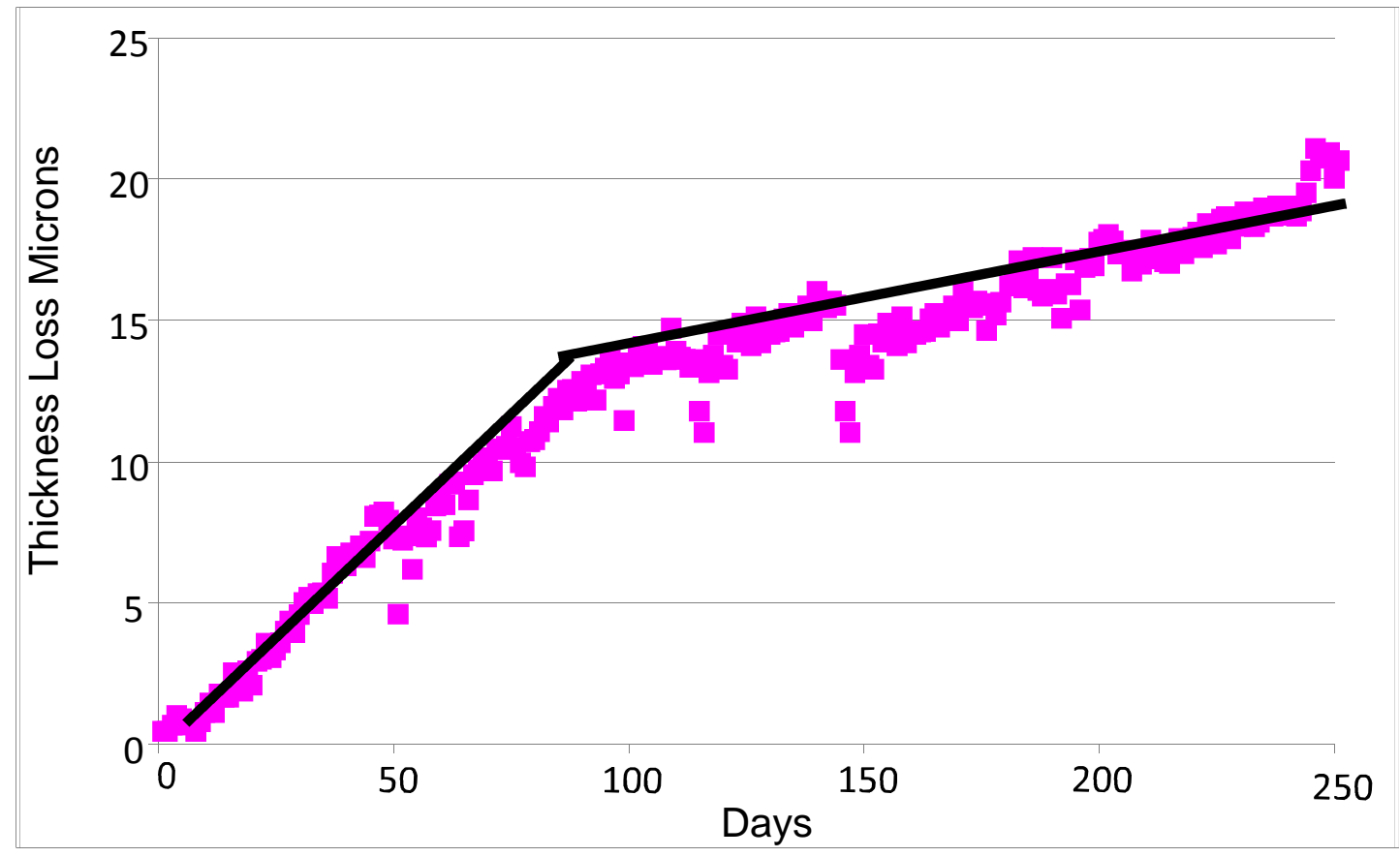

Figure 24 Measured thickness loss at Bridge 62 near 'East Kilmore' in Victoria 


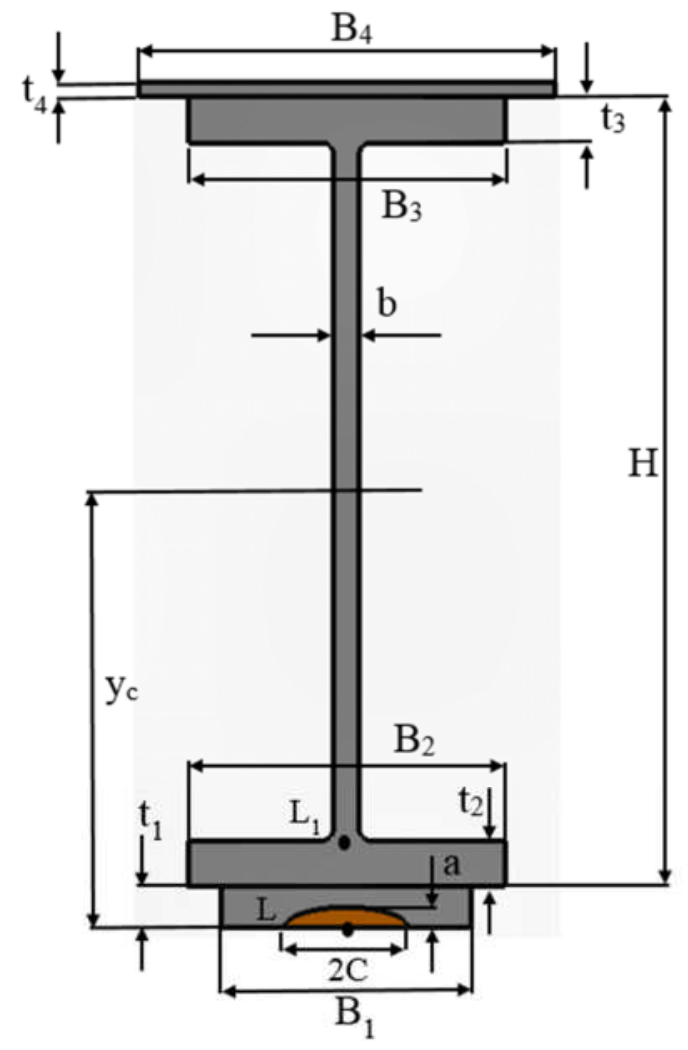

Figure 25 Graphical representation of the corroded I beam 

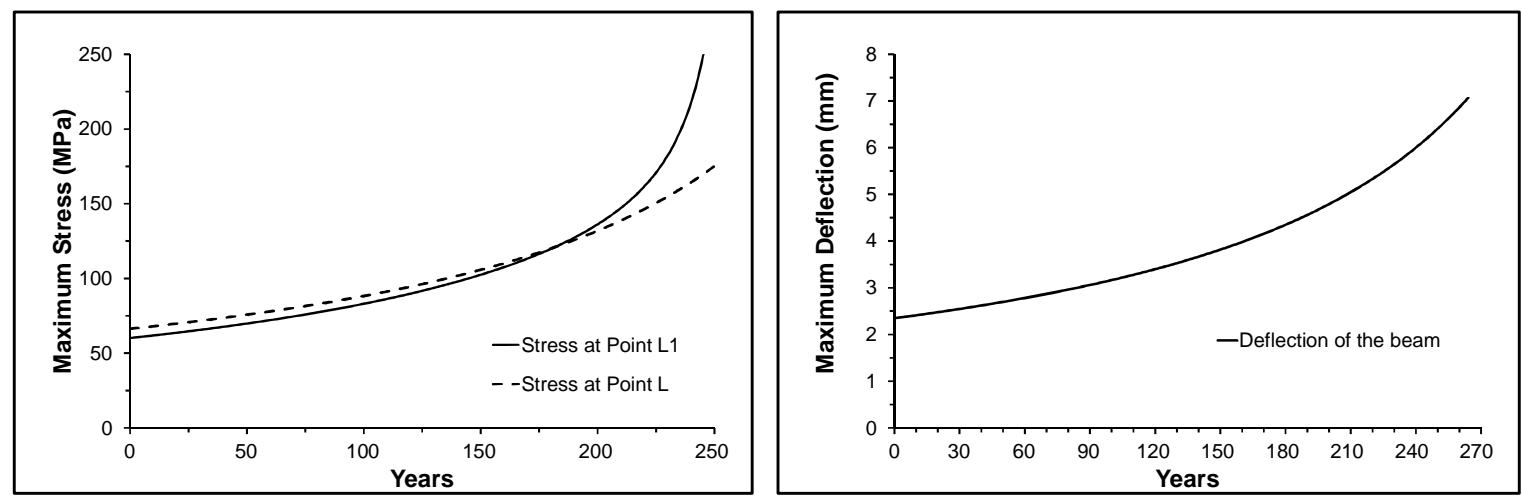

Figure 26 Bridge 62: a). Increase in maximum stress with time, b). Increase in maximum deflection with time
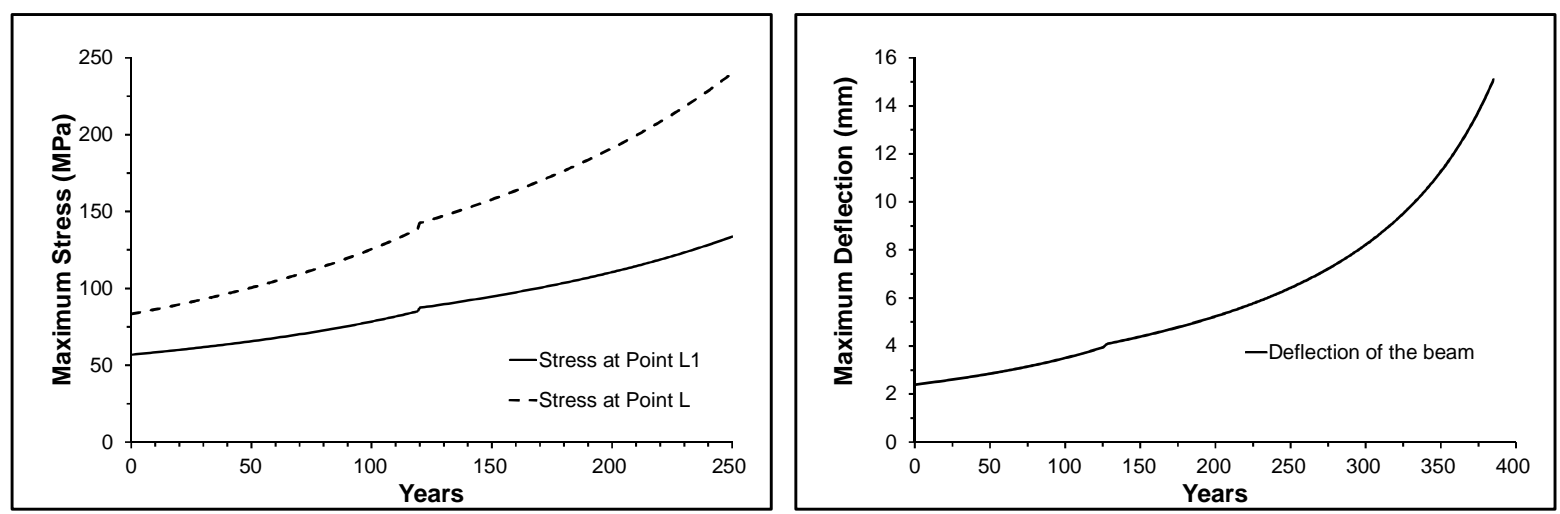

Figure 27 Bridge 44: a). Increase in maximum stress with time, b). Increase in maximum deflection with time 


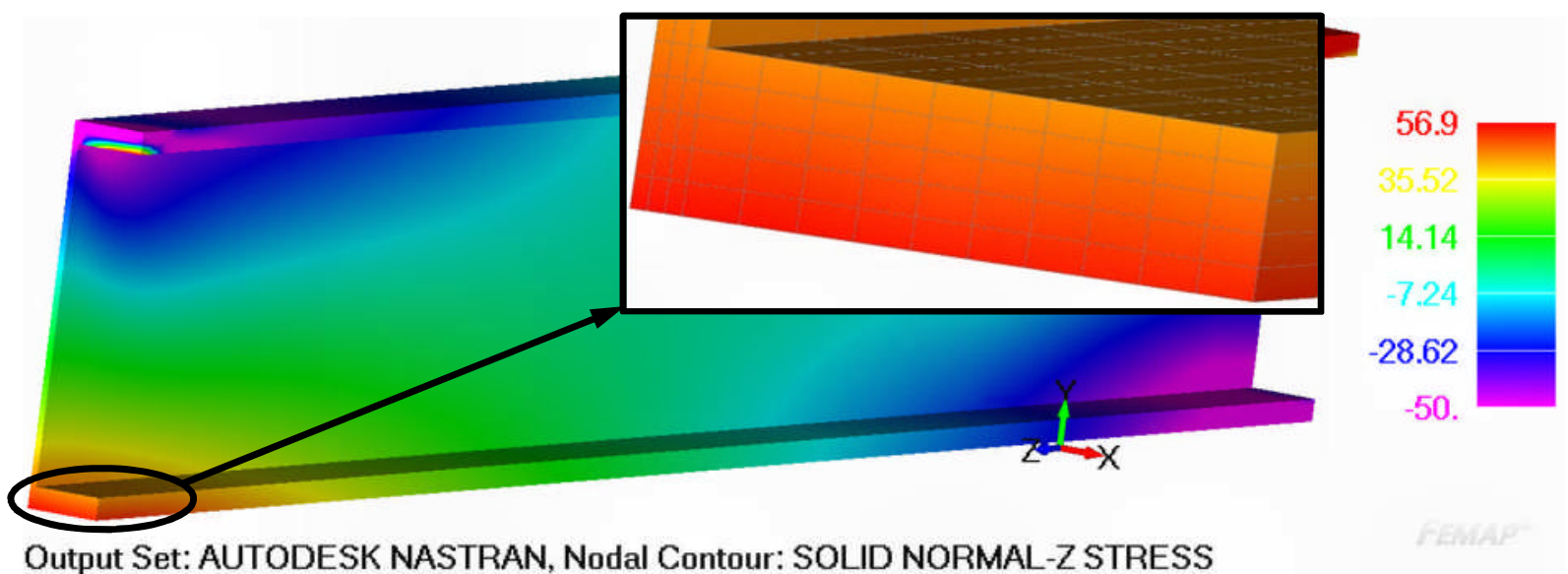

Figure 28The maximum stress plot, in MPa, for bridge 62 .

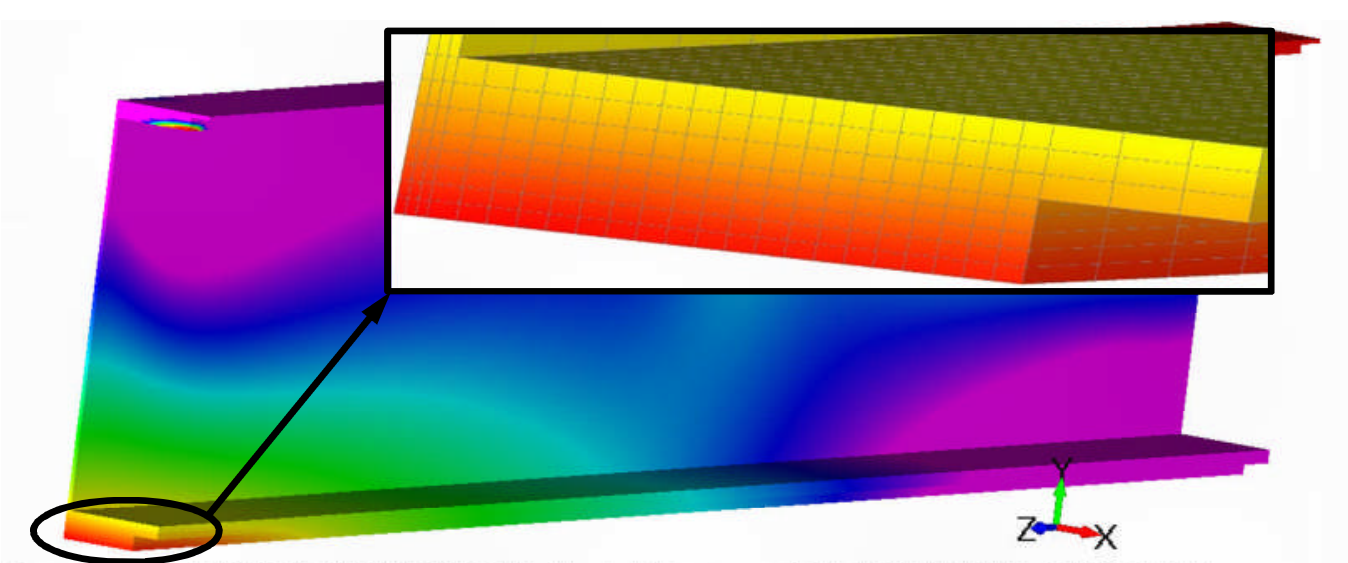

83.4

36.04

12.36

$-11.32$

-35 .

Output Set: AUTODESK NASTRAN, Nodal Contour: SOLID NORMAL-Z STRESS

Figure 29 The maximum stress plot, in MPa, for bridge 44 . 


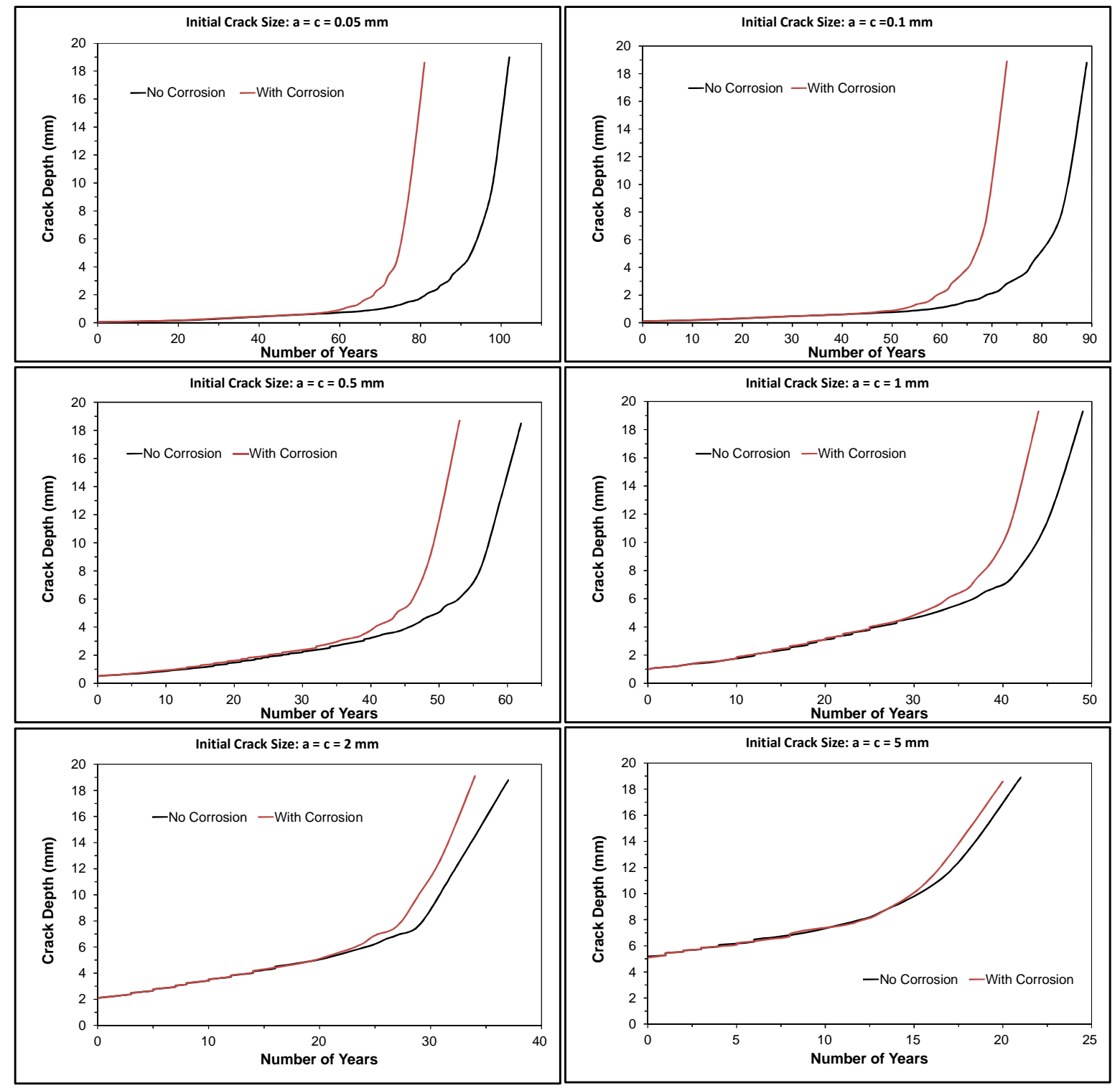

Figure 30 The resultant computed crack growth histories for Bridge 62 

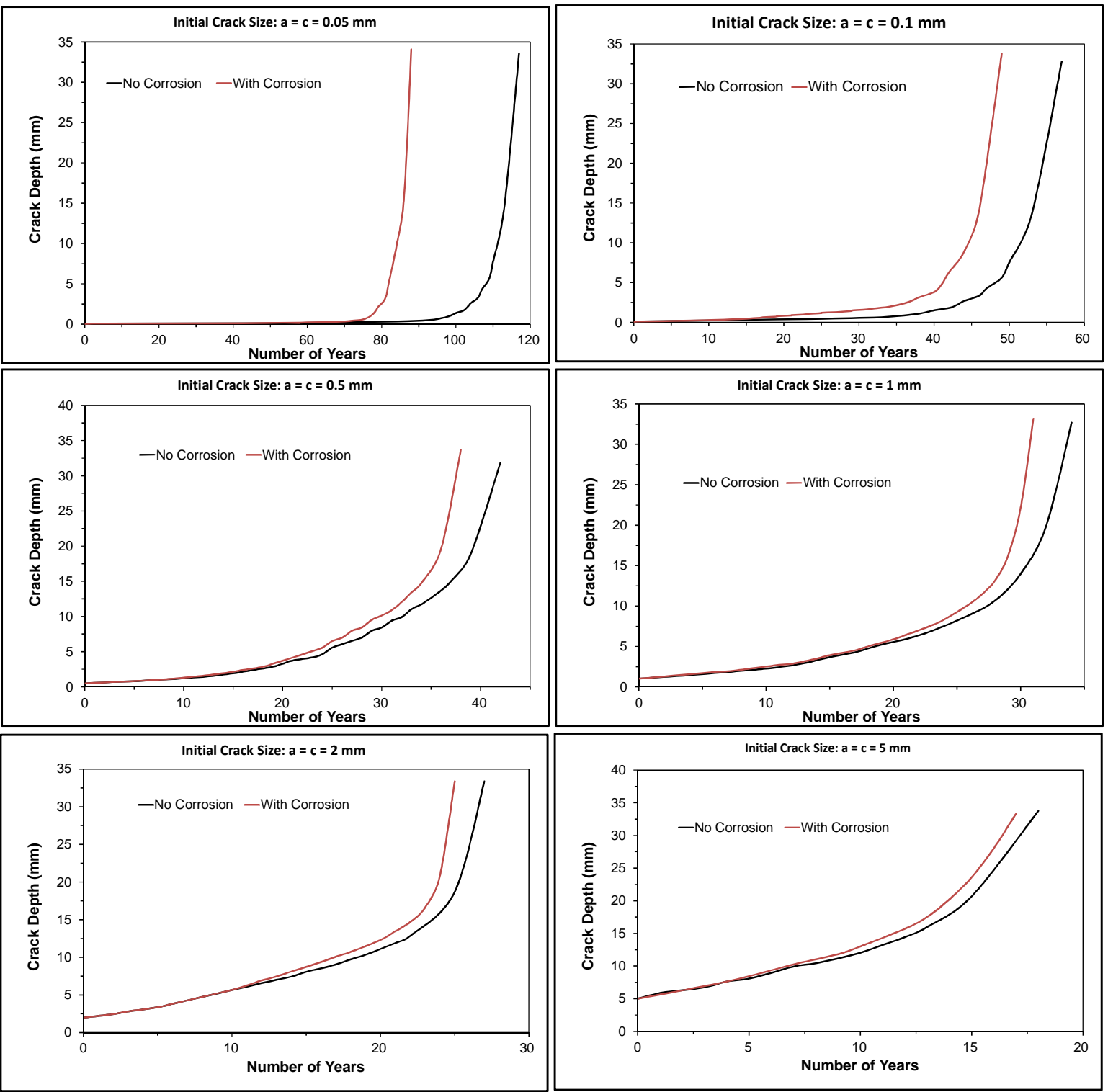

Figure 31 The resultant computed crack growth histories for Bridge 44 


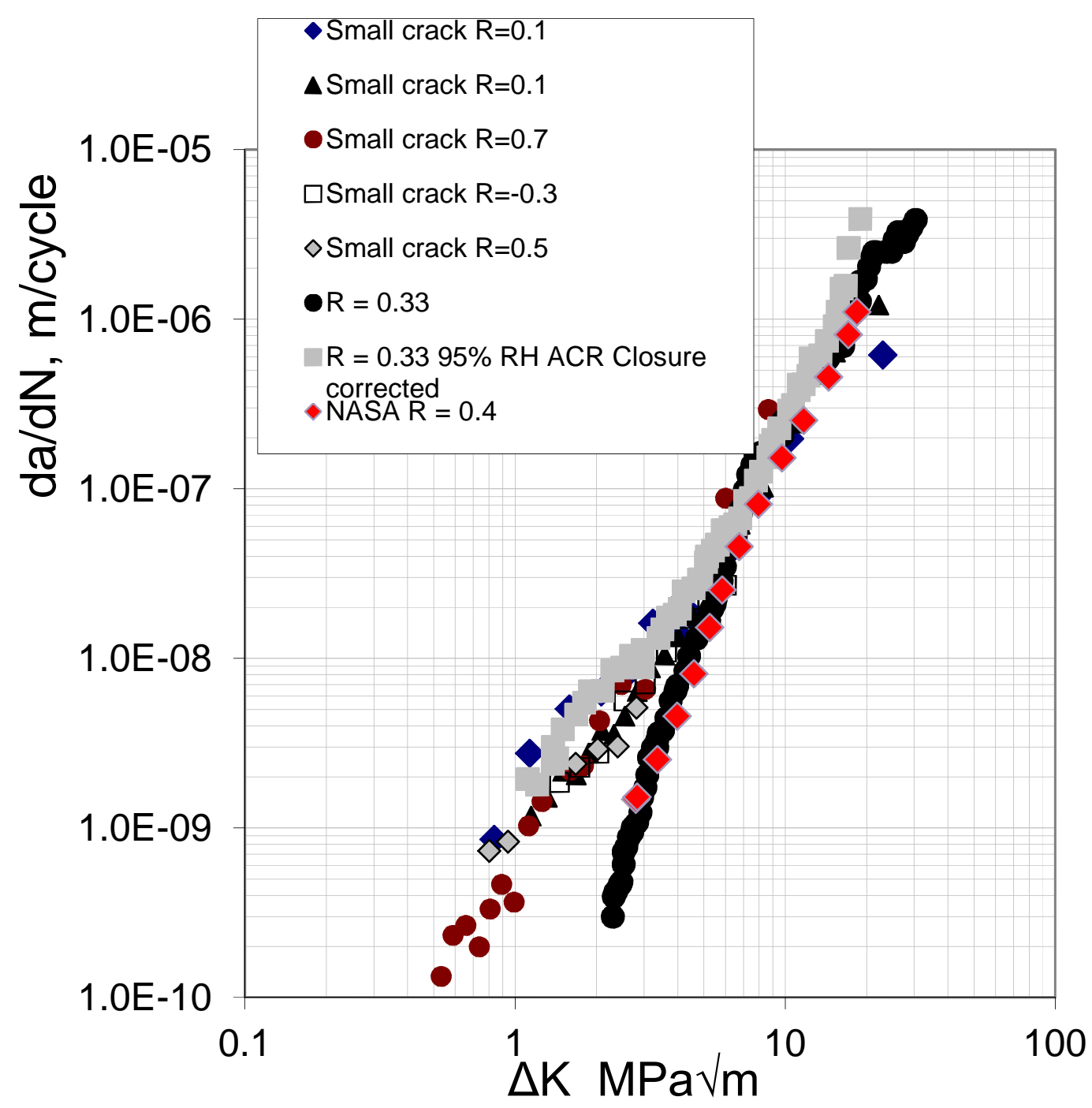

Figure A1 Comparison of long and small crack growth data for a range of R ratio's 


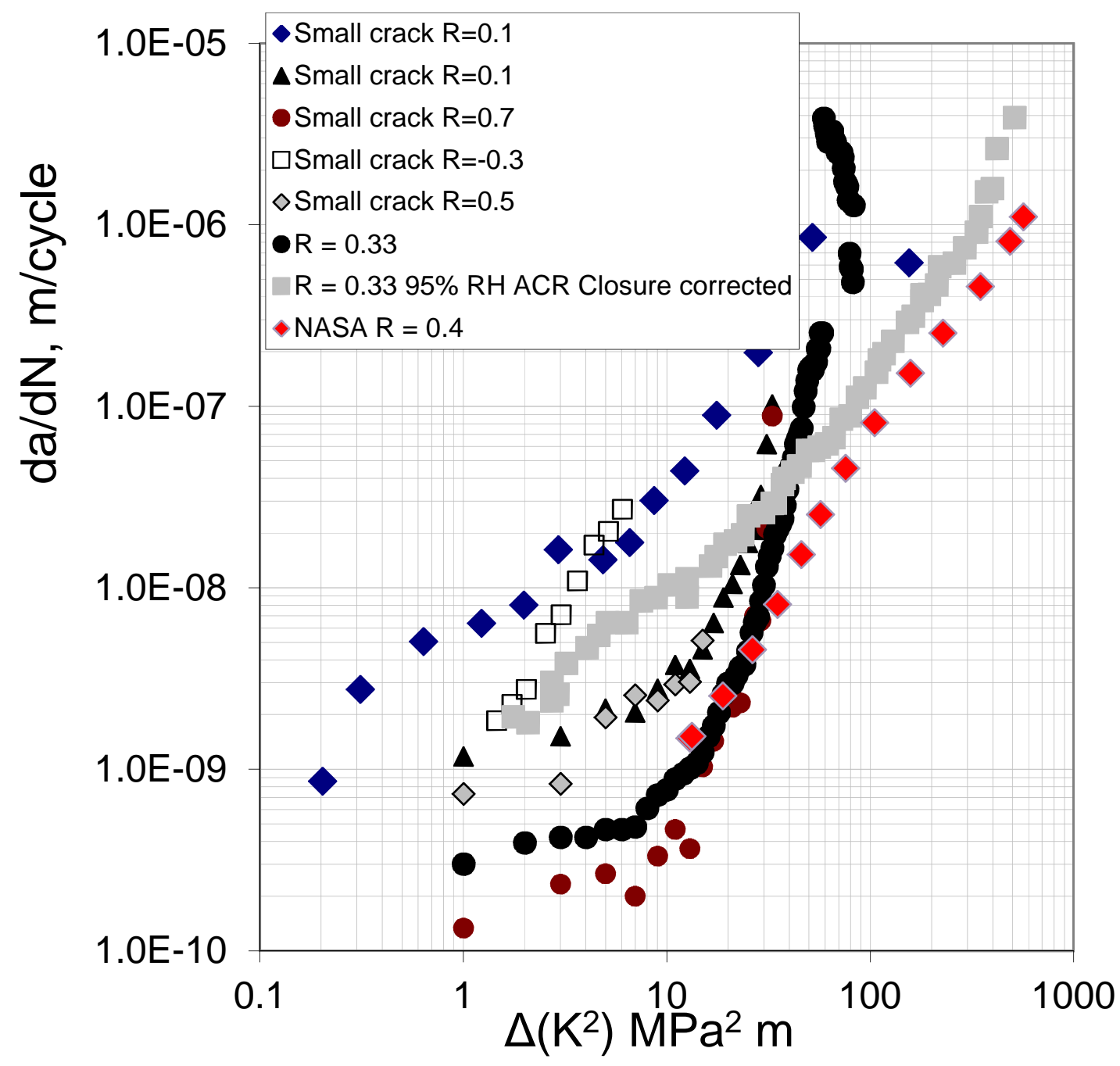

Figure A2 Comparison of long and small crack growth data replotted as a function of $\Delta\left(\mathrm{K}^{2}\right)$ 
Table 1: Data on trains using UP line for Bridge 62 and Bridge 44

\begin{tabular}{|c|c|c|c|c|c|c|}
\hline \multirow[b]{2}{*}{$\begin{array}{l}\text { Train } \\
\text { Type }\end{array}$} & \multicolumn{3}{|c|}{ Bridge 62} & \multicolumn{3}{|c|}{ Bridge 44} \\
\hline & $\begin{array}{l}\text { No } \\
\text { per } \\
\text { Week }\end{array}$ & $\begin{array}{l}\text { Total } \\
\text { Weight/Week }\end{array}$ & $\begin{array}{l}\text { Total } \\
\text { Weight }\end{array}$ & $\begin{array}{l}\text { No per } \\
\text { Week }\end{array}$ & $\begin{array}{l}\text { Total } \\
\text { Wt/Week }\end{array}$ & $\begin{array}{l}\text { Total } \\
\text { Weight }\end{array}$ \\
\hline Ore Train & 7 & 14896 & 774592 & 5 & 10640 & 553280 \\
\hline $\begin{array}{l}\mathrm{N} \text { Class } \\
\text { Passenger }\end{array}$ & 14 & 5852 & 304304 & 10 & 4180 & 217360 \\
\hline Sprinter & 14 & 1680 & 87360 & 10 & 1200 & 62400 \\
\hline $\begin{array}{l}\text { Estimated } \\
\text { Total in } \\
\text { one year }\end{array}$ & & & 1166256 & & & 833040 \\
\hline
\end{tabular}

Table 2 Loss of material per year

\begin{tabular}{|l|l|}
\hline Location & Corrosion rate $(\mathrm{mm} /$ year $)$ \\
\hline East Kilmore, Bridge 62 & 0.024 \\
\hline Little River, Bridge 44 & 0.053 \\
\hline Clayton, Melbourne & 0.015 \\
\hline & \\
\hline
\end{tabular}

Table 3: Dimensions of the Bridge 62 and Bridge 44 girders

\begin{tabular}{|l|l|l|}
\hline Dimensions & $\begin{array}{l}\text { Bridge 62 } \\
(\mathrm{mm})\end{array}$ & $\begin{array}{l}\text { Bridge 44 } \\
(\mathrm{mm})\end{array}$ \\
\hline $\mathrm{B}_{1}$ & 0.0 & 229.0 \\
\hline $\mathrm{B}_{2}=\mathrm{B}_{3}$ & 152 & 246.0 \\
\hline $\mathrm{B}_{4}$ & 0.0 & 304.0 \\
\hline $\mathrm{t}_{1}$ & 0.0 & 22.2 \\
\hline $\mathrm{t}_{2}=\mathrm{t}_{3}$ & 22 & 19.6 \\
\hline $\mathrm{t}_{4}$ & 0.0 & 6.35 \\
\hline $\mathrm{H}$ & 381.0 & 609.6 \\
\hline $\mathrm{b}$ & 12.0 & 11.9 \\
\hline
\end{tabular}




\title{
LIFE CYCLE ANALYSIS OF STEEL RAILWAY BRIDGES
}

\author{
D. Peng ${ }^{1}$, R. Jones ${ }^{1,2}$, K. Cairns ${ }^{1}$, J. Baker ${ }^{1}$, F. Berte ${ }^{3}$, A. McMillan ${ }^{2}$
}

${ }^{1}$ Centre of Expertise in Structural Mechanics, Department of Mechanical and Aeronautical Engineering, Monash University, Wellington Rd, Clayton, Vic 3800, Australia

${ }^{2}$ School of Applied Sciences, Computing and Engineering, Wrexham Glyndwr University, Mold Road, Wrexham, LL11 2AW, UK.

${ }^{3}$ Norwegian University of Science and Technology - NTNU, Department of Engineering Design and Materials, Trondheim, 7491, Norway

\begin{abstract}
This paper focuses on the growth of cracks that arise from natural corrosion in steel bridges. It is shown that these two effects of corrosion and stress, need to be simultaneously analysed. A methodology used to compute the growth of such cracks in bridge steels is presented. A better understanding of the remaining life of steel bridges would help establish an assessment procedure and guide engineers when deciding between reinforcement and replacement.
\end{abstract}

Keywords: steel bridges, corrosion, fatigue crack growth, remaining life

\section{INTRODUCTION}

Bridge condition can typically be expressed in two ways: condition appraisal (which is subjective) and analytical load rating. Condition appraisal is perhaps the most commonly used approach. The appraisal is a subjective rating based on established guidelines such as the National Bridge Inspection Standards (NBIS) and the inspector's judgment. Analytical load rating is also used to evaluate railroad bridges. The American Railway Engineering and Maintenance-of-Way Association (AREMA) publishes the Manual for Railway Engineering, which provides standards for railroad bridge evaluation [1]. In general, steel bridge structures must not only comply with enough strength but also behave satisfactorily under services loads ${ }^{1}$.

The assessment of the safety, durability and remaining life of steel bridges requires an understanding of the interaction of fatigue and corrosion degradation processes. In tension dominated members, there is a competition between the rate at which material is lost due to corrosion and the rate of fatigue crack growth. However, at present there is little information about the environments seen by Australian and Norwegian bridges or the associated rates of corrosion. In Australia the fatigue analysis of new and existing steel structures is based on the use of standardized S-N curves. To be able to provide an estimated life remaining for corroded steel bridge is very important for the infrastructure industry. A better understanding of the real behaviour of steel bridges would help establish an assessment procedure and guide engineers, when deciding between reinforcement and replacement.

\footnotetext{
${ }^{1}$ In this context it should be noted that there are numerous approaches to repair cracking and degradation in steel bridges. Many different methods ranging from the stop drilling of holes [3-6] to the use of composite doublers [6, 7] are used.
} 
Numerous publications can be found on corrosion fatigue, and a detailed discussion is provided in [2]. There are only a few available publications for solving the problems of fatigue-corrosion interaction in steel bridges. A probabilistic approach and damage stress model to evaluate fatigue lives was developed in [8]. Many of the methods used focus on the use S-N curves for different atmospheric conditions coupled with assumed corrosion rates and simple cumulative fatigue damage laws [9, 10]. A fatigue crack growth evaluation method based on linear elastic fracture mechanics was developed in [11-15]. No available solutions can be found in the literature for corrosion-fatigue interaction where the section stress changes as material is lost due to corrosion.

Fatigue life prediction of corroded bridge steel beam is exceptionally difficult and computationally demanding, as calculations need to be made at each stage of the life of a beam. This is due to compute the stress intensity factor computations for each crack configuration that are needed to calculate the amount of crack growth, update the crack geometry, and then re-compute the stress intensity factors for this new geometry. To meet this challenge, this paper will discuss the issues associated with fatigue crack growth within corroded steel beam. The methodology addresses the following areas and develops the tools and procedures needed by industry:

1) A methodology for determining the load environment seen by steel bridges (i.e. the load spectra or load time history). It is illustrated by examining two bridges, viz: V/Line Brides 62 and Brides 44.

2) Tools for determining the operational environment seen by bridges.

3) A methodology for determining the corresponding rates of corrosion.

4) Tools for assessing the damage state of a bridge and for assessing the interaction of corrosion with the structure and the operational load spectra.

5) The fatigue crack growth tools which when coupled with an ability to monitor the rate of corrosion enable the operator to assess whether a bridge will fail via reduction in the net section or by fatigue crack growth. This then enables the operator to determine the appropriate maintenance periods.

In steps 4) and 5), a 3D model of the steel bridge beam without corrosion is created and the region of interest analysed. In this model, the crack is not explicitly modelled. Having determined the stress field with a semi-analytical solution technique [14, 17], conjunction with crack size modification factor and geometry evolution factor (varied with corrosion rate), was used to determine the stress intensity factors $(\mathrm{K})$ for any given crack length. These stress intensity factors were used in conjunction with the Hartman-Schijve crack growth equation [15, Error! Reference source not found.] to compute the crack growth history which can be thought of as a variant of the strain energy density formulation presented in [17, 18] and discussed in more detail in the Appendix. An advantage of this approach is that cracks in the structure do not need to be explicitly modelled. A crack of any size can be analysed using the original (un-cracked) finite element model. As cracks are not modelled explicitly, a coarser mesh can be used to minimise the number of degrees of freedom, thereby reducing the analysis time. Solutions for the stress-intensity factors can then be obtained for a variety of cracks using the original finite element analysis quickly and easily. 
The data presented in this paper supports the ASHTO recommended metal loss model. The paper also reveals that the failure assessment of steel bridges needs to account for the interaction between fatigue crack growth and the stress increase created by corrosion due to the reduction in the section thickness.

\section{DETERMINING THE LOADING SPECTRA}

This section describes a method for determining fatigue analysis spectrum with REPOS (Road Environment Percentage Occurrence Spectrum) diagrams of Bridge 62 near 'Kilmore East', see Figure 1 and Bridge 44 (Western Line) near 'Little River', see Figure 2. The locations of the V/Line Bridges 62 and 44, both of which are just outside Melbourne, Victoria, are provided in Figure 3.

Figure 4 shows the selection of beams for Bridge 62 and the instrumentation of strain gauge as well as the location of the eight strain gauges, the inactive gauges for the half bridge arrangement and terminal blocks for connecting necessary wiring looms. The bridge has two rail tracks, each of which is supported by four girders with $4.87 \mathrm{~m}$ length. Four active strain gauges were installed on each beam. Additionally, a further eight strain gauges were bonded to two small plates which in turn were bonded to the webs of the reference beam and test beam. The purpose of these strain gauges was to make up one arm of the half bridge and compensate for any variation in temperature. The positioning of the active strain gauges was such that they could be considered as pairs. The active strain gauge pairs were 1 and 5,2 and 6,3 and 7,4 and 8 .

There are three bridges spanning a low lying area just east of Little River in Victoria. One of these bridges is managed by ARTC (Australian Rail Track Corporation). The other two bridges are managed by V/Line (Australia's largest regional public transport operator). For ease of reference, the two V/Line bridges are called Bridge 44, see Figure 2. The UP line of Bridge 44 is supported by two girders with $6.57 \mathrm{~m}$ length. The rail track on the UP line (i.e. to Melbourne) is supported by spaced wooden sleepers which in turn are supported by two large girders. The rail track on the DOWN line (i.e. to Geelong) is supported by a concrete decking, all of which is supported by four girders. The UP and DOWN lines both have two spans. The fatigue analysis provided in this paper will focused on UP line of Bridge 44. Figure 5 and Figure 6 show the selection of beams on which the strain gauges were installed. All strain gauges were located on the top side of the lower flange.

We first analysed the raw data of this module to assess the quality of the data. This was done using a Fast Fourier Transformation (FFT) to do frequency filtering. To further reduce the run time associated with fatigue analysis, the amplitude cutoff filtering technique was used to process the data after frequency filtering. Finally, a 'Rainflow' algorithm was employed to create the REPOS matrix.

The measured stress history associated with ore trains, see Figure 7, N-Class locomotives and Sprinter 1 are shown in Figures 8-10. The data was processed using FFT, see Figures 11-13. Noted: The sample rate was 0.002 and the Nyquist frequency was $250 \mathrm{~Hz}$. The dominant responses are below $\sim 50 \mathrm{~Hz}$, and the amplitude of the signal components is very much lower for frequencies higher than $50 \mathrm{~Hz}$. To remove electromagnetic or electrical noise that may have been recorded in the data acquisition, a low-pass digital filter was used to reduce the strain data recorded from the strain gauges. 
The "cutoff" frequency was chosen as $20 \mathrm{~Hz}$, see Figures $14-16$. It is obvious that the frequency filtering analysis techniques may not be good enough to eliminate all noises. Consequently another tool was used to remove this noise with lower amplitude.

This routine discards any cycles that are below a given threshold value. To analyse this data and extract the REPOS a generic rainflow program has been written. This program can handle any large data structure and was extensively validated against spectra obtained from the Australian Department of Defence and from General Motors. In this approach, it is assumed that the speed of the loading does not influence the fatigue life. The fatigue life prediction does not use the time variable of the signal. The data contained in the time series are taken at uniform time intervals. That means there are several data points between the peaks and valleys. It is necessary to use data reduction techniques, such as rainflow algorithm, to analysis the raw data. As the time series must only contain the peaks and valleys with no data points in between, a compression method called "peak and valley summary" has been used to delete these intermediate points from the time series. Also, there is no influence on the result of the bridge fatigue life prediction for the cycles in loading spectrum with small amplitude. As a result, another tool was used to further reduce the raw data. This routine discarded any cycles that were below a given a threshold value, while retaining the overall sequence of the loading.

The resultant "filtered" data will subsequently be used to perform bridge 62 near "Kilmore East' loading spectrum generation. The method for generating bridge 44 loading spectrum is the same as the method used for bridge 62. To minimise repetition, we have not provided the Load time history curve for the raw data and results of FFT for bridge 44 . The data of loading and train frequency for $\mathrm{V} /$ Line rail Bridge 62 and Bridge 44 have been gathered, see Table 1 . The Up line, i.e., the line towards Melbourne carried an estimated total of 1.17 and 0.833 million gross tonnes per year for bridge 62 and bridge 44 respectively, see Table 1 . These were made up of passenger trains, including trains pulled by $\mathrm{N}$ Class locomotives, sprinter carriages and ore train. The most heavily laden train is the ore train. It should be noted that all weights was in tonnes, the numbers listed in Table 1 were the average number of wagons or carriages. The ore trains were fully laden and the passenger trains only included normal passenger loads.

Figures 17 and 18 show the 3D distribution of the percentage of occurrences related to the "Bridge 62 near Kilmore East and Bridge 44 near Little River Load Spectrum". The represented by the REPOS ((Road Environment Percentage Occurrence Spectrum)) arrays used in this crack growth analysis.

\section{ENVIRONMENTAL DATA FROM BRIDGE 62}

The life of steel girder rail bridges is determined, in part, by corrosion and fatigue cracking. The sub-structure of the bridge was subjected to significant moisture and resulting corrosion during the wet seasons. Before assessing the coupled effect of corrosion and fatigue, a knowledge of the rate of corrosion is needed. In this paper, we will adopt the American Association of State Highway and Transportation Officials (AASHTO) recommended metal loss model [Error! Reference source not found., 20] which states that the metal loss versus time curve is bi-linear, see see Figure 19. However, as seen in Figure 19, there is little actual data to support this model and the data shown in Figure 19 is not particularly convincing. This approach to assessing the "steady state" corrosion rate is consistent with the International Standard Corrosion of Metals and Alloys - Corrosivity of Atmospheres, ISO 
designation 9224 [21], which specifies guiding values of corrosion rate for metals exposed to the atmosphere consisting of an average corrosion rate during the first 10 years of exposure. A detailed review of the corrosion of bridge steels, the AASHTO and ISO corrosion standards and documented steady state corrosion rates associated with a range of locations and steels is in given in [22].

One problem with aging bridges is that if there is any serious corrosion it is likely to have developed over a reasonable number of years. However, to know its significance we need to know how fast the bridge is corroding, i.e. its corrosion rate, at this moment in time. That said, we do not have the luxury of placing corrosion sensors or weight loss samples on a bridge and wait for 5 or more years until the sensors/samples themselves reach the steady state corrosion rate that the bridge is seeing.

The advantage of the AASHTO bi-linear approach is that once the bridge is behaving like the metal loss versus time curve on the line AB, see Figure 19, we know the long term corrosion rate without having to monitor the bridge for years. For bridges, this can be done in the order of four to twelve months using electrical resistance corrosion sensors [22].

In order to obtain the rate of corrosion, two University of South Australia (Uni SA) Data Loggers, Units 5 and 9, were installed on Bridge 44 in a stainless steel cage, see Figure 20. The loggers, with a primary aim of recording corrosion rates of attached corrosion sensor boards and environmental information, Data Logger software configuration was confirmed at V1.8 and both units had been proven serviceable. Unit 9 had an Australian Defence Science and Technology Group (DST Group) Sensor T1 installed in an exposed position between two sleepers to reduce physical damage and a CSIRO Time of Wetness [ToW] indicator wired into a Monash sensing circuit. Logger unit 5 had sensor BF10 installed in a sheltered position underneath a sleeper and then upside down.

Similar to Bridge 62, two Uni SA Data Loggers, Units Seven and Three, were installed on bridge 62 in a stainless steel cage. The loggers, were configured with V1.8 software and both had been proven to record and download data. Unit 7 had DST Group (Defence Science and Technology Group) Sensor (6F11), see Figure 21, installed in an exposed position on top of one of the beams supporting the exposed steel corrosion plates and a CSIRO (Commonwealth Scientific and Industrial Research Organisation) Time of Wetness [ToW] indicator wired into a Monash sensing circuit. Logger Unit 3 had sensor 5F10 installed in a sheltered position underneath the bridge deck on the same support pole but inverted.

The steel samples were attached to a "Skeleton" bridge structure and secured by two steel fasteners per plate. Two plates had a failed fastener each and had been realigned sideways. The ToW sensors were secured and suitably exposed. Data was downloaded from both loggers using the Uni SA Sensor Tool programme and the Graphical User Interface programme. The extreme vibration of the skeleton bridge could be the source. The data was downloaded multiple times to validate integrity. Raw data was downloaded with Uni S.A. "Sensor Tool" then extracted with "Data Extractor". The benefits of this process include less chance of corruption during the download and collation of all the sensor resistive values in one table rather than chronologically distributed through the data when extracted with the GUI. The GUI has been reissued to reduce but not eliminate this extra step.

The loggers were configured to record environmental information, temperature and relative humidity, every 30 minutes, whilst the absolute sensor resistance was measured every 24 hours. Environmental data consumed the bulk of data logger memory which translated to 
some two months for the $128 \mathrm{k}$ bytes. By reconfiguring the environmental sampling period from 30 minutes to one hour, the period between down loads can be extended to four months and this was done for all four data loggers. Visit periodicity is now determined by the risk of vandalism and data loss from vandalism.

The temperature reference strip on both exposed sensors is sealed in an epoxy sheath. The sheath is translucent and corrosion can be seen to be growing on both exposed sensors.

The corrosion rate data must be collected over an extended period to give an accurate value and the process cannot be hurried: this is the critical time path in the data collection process. The load data, the frequency of loading and how the load is applied must be gathered over a representative period to give reliable results. In the present study the load data and the lossof-material-to-corrosion data was collected over a period of approximately 18 months.

To illustrate this, Figures 22-24 present metal loss measured using a steel electrical resistance corrosion sensor at Monash in Metropolitan Melbourne, Bridge 44 on the Little River, which is on the coast between Melbourne and Geelong, and Bridge 62 at Kilmore East which is inland in Victoria, Australia, see Figure 3. Figures 22-24 substantiate the NCHRP (National Cooperative Highway Research Program) and AASHTO formulation and the advantage gained in real time monitoring of a rail bridge to obtain the long term corrosion rate. The steady state corrosion rates determined in these tests are presented in Table 2 . These rates are consistent with those documented in [22].

The results of this study support the AASHTO standard for the loss of metal seen by steel bridges. As such, the AASHTO bi-linear relationship between metal loss and the time in service provides a simple method for estimating the corrosion rates associated with aging structures. It is also shown that corrosion sensors can be used to determine the metal loss versus time relationship and hence can play an important role in any bridge management system.

\section{FATIGUE CRACK GROWTH WITH CORROSION EFFECT MODEL}

\subsection{Failure Due To Material loss (Corrosion)}

Corrosion of steel bridge girders will be a maximum where electrolyte can "wick" between the transom and the girder compression flange or where electrolyte is trapped by some other means. The worst case scenario is loss of material from the web, top flange and bottom flange. A graphical representation of the corroded I beam as well as a diagram showing a semi-elliptical crack in corroded I beam is provided in Figure 25. The dimension of the girders are given in Table 3. From direct measurement, the top side of the lower flange fibre stress for bridge 62 is $50.3 \mathrm{MPa}$ and for Bridge 44 is $62.3 \mathrm{MPa}$ respectively.

The distance from the beam neutral axis to the extreme flange fibre $y_{c}$ and the Moment of Inertia about the neutral axis I can be calculated from the relation

$$
\begin{gathered}
y_{c}=\frac{\sum_{i=1}^{5} t_{i} B_{i}\left(\sum_{j=1}^{i-1} t_{j}+\frac{t_{i}}{2}\right)}{\sum_{i=1}^{5} t_{i} B_{i}} \\
I=\sum_{i=1}^{5}\left\{\frac{B_{i} t_{i}^{3}}{12}+B_{i} t_{i}\left[y_{c}-\left(\sum_{j=1}^{i-1} t_{j}+\frac{t_{i}}{2}\right)\right]\right\}
\end{gathered}
$$


The outer flange fibre stress in beams subject to bending can be:

$$
\sigma_{L}=M y_{c} / I
$$

where $\sigma$ is the stress, $\mathrm{M}$ is the applied Moment. The shear stress at point $L_{l}$ as shown in as Figure $25 \tau_{L_{1}}$.

$$
\tau_{L_{1}}=Q S^{*} /\left(I B_{3}\right)
$$

Where $S^{*}$ is first moment of the area and it can be calculated from the equation

$$
S^{*}=\sum_{i=1}^{2} t_{i} B_{i}\left(y_{c}-\frac{t_{i}}{2}\right)-t_{1} t_{2} B_{2}
$$

The normal stress at point $L_{1}$ as shown $\sigma_{L_{1}}$ can be easy obtained from equation (5):

$$
\sigma_{L_{1}}=M\left(y_{c}-t_{1}-t_{2}\right) / I
$$

Let's name the maximum principle stress at points $\mathrm{L}$ and $\mathrm{L}_{1}, \sigma_{L}$ and $\sigma_{1}\left(L_{1}\right)$. Then, the stresses $\sigma_{L_{1}}$ and $\tau_{L_{1}}$ can be used to calculated the stress $\sigma_{1}\left(L_{1}\right)$. Therefore, the maximum stress in I beam is given by

$$
\sigma=\operatorname{Max}\left[\sigma_{L}, \sigma_{1}\left(L_{1}\right)\right]
$$

The limits are the as-new girder measured stress and the material yield stress. If the measured corrosion rate for bridge steel I beam is $\xi$ (mm/year), the maximum stress in I beam $\sigma$ is function of the corrosion rate $\xi$. From the equation of $\sigma=\sigma_{y}\left(\sigma_{y}\right.$ is the yield stress for the steel), the relationship between the flange stress, allowing for the loss of material due to corrosion, and operational life can be obtained.

The relationship between the maximum stress, allowing for the loss of material due to corrosion, and operational life are given in Figures 26 and 27. The yield stress for this steel was conveyed by V/Line staff to be approximately $240 \mathrm{MPa}$. This implies that retirement resulting from corrosion from an as-new state is approximately 244 years for Bridge 62, see Figure 26(a). Whilst in bridge 44 is approximately 250 years, see Figure 27 (a). It is also obvious that the loss of girder material due to corrosion has more effect on the web, than on the flange. This causes a larger percentage decrease in shear capability, than in bending capability for Bridge 62 . Whilst in bridge 44, stress at point $\mathrm{L}$ is always higher than the stress at point $\mathrm{L}_{1}$ for any time.

Increase in maximum deflection with time are also shown in Figures 26(b) and 27(b). As mentioned in [24], the deflection requirement of deflection limits of a railway bridge for serviceability limit state under live load plus dynamic load allowance shall not be greater than $1 / 640$ of the span. It is obvious that deflection in this analysis is not a safety issue for Bridge 62. In contrast, for the Bridge 44 , the time ( 160 years) of its deflection reaching limit is happening before the bridge steel yield as corrosion ( $\sim 250$ years $)$. 
These results revealed that failure due to material loss (Corrosion) determined merely by outer flange fibre stress of girder is not enough. The stress at different point and deflection also needs to be considered dependent on the section of the girder.

\subsection{Failure due to combined action of corrosion and cracking}

If we are to assess damage in Australian Rail bridges, it is important to establish the crack growth tools developed can be used to accurately predict crack growth, in a representative structural member under a complex load time spectra.

Since the life of the corroded steel bridge is a strong function of the corrosion rate, in this paper, the interaction of combined corrosion and crack growth has been considered. To avoid a computationally intensive process of traditional stress intensity factors calculation method, an alternative and simple approach has been used in this paper to get stress intensity factors. It is assumed that the stress intensity factor for the crack in corroded steel beam $K_{I}$ can be expressed as: per Eq. (6):

$$
K_{I}(a, c)=F_{\sigma} K_{I(\text { Original })}\left(a^{*}, c^{*}\right)
$$

Here, $F_{\sigma}$ is the geometry evolution factor. The stress intensity factor $K_{I(\text { Original })}\left(a^{*}, c^{*}\right)$ is obtained by using the method provided by $[11,14]$. The $(\mathrm{a}, \mathrm{c})$ and $\left(\mathrm{a}^{*}, \mathrm{c}^{*}\right)$ are the crack size of without and with corrosion and its dependency can be expressed as, see Figure 25.

$$
\begin{aligned}
& a^{*}=a-\xi N \\
& c^{*}=c \sqrt{1-(\xi N / a)^{2}}
\end{aligned}
$$

The geometry evolution factor $F_{\sigma}$ is determined with the following equation:

$$
F_{\sigma}=\frac{2 y^{*}-t^{*} I}{2 y-t I^{*}}
$$

Having determined a solution for the SIF (Stress Intensity Factors), the next step is to apply this to the integration of crack growth over the remaining life of the bridge.

Having the results from previous approach [23] thus shown that:

i) It appears that, in general, effect of the environment initiates corrosion damage and grow cracks during periods of inactivity as oppose to during transit of a train;

ii) that the growth of both small and long cracks can be unified by expressing $\mathrm{da} / \mathrm{dN}$ as a function of $\Delta \mathrm{K}-\Delta \mathrm{K}_{\mathrm{thr}}$, as first suggested by Hartman and Schijve [15], rather than $\Delta \mathrm{K}$.

The crack growth model used in this paper is based on a variant of the Hartman-Schijve [15] concept, i.e. that $d a / d N$ should be dependent on the amount by which $\Delta K$ exceeds the fatigue 
threshold $\Delta K_{t h r}$ of the material under the associated test environment, to investigate a variant of the original Hartman-Schijve equation, viz:

$$
d a / d N=D\left[\left(\Delta K-\Delta K_{t h r}\right) / \sqrt{ }\left(1-K_{\max } / \mathrm{A}\right)\right]^{\eta}
$$

where is a constant that is generally approximately 2 . Corrosion rate data must be collected over an extended period to give an accurate value and the process cannot be hurried: this is the critical time path in the data collection process. The load data, the frequency of loading and how the load is applied must be gathered over a representative period to give reliable results. A pilot sample of load data and 18 months of the loss-of-material-to-corrosion data was collected.

Analysis of the measured steady state corrosion data gave a state corrosion rate of $\xi=0.024$ $\mathrm{mm}$ per year for Bridge 62 and $\xi=0.053 \mathrm{~mm}$ per year for Bridge 44 . The crack growth characteristics are similar to the various (representative) bridge steels analysed in [23], viz. $D$ $=1.5 \times 10^{-10}, \mathrm{~A}=140 \mathrm{MPa}$ and $\eta=2$. ASTM E647-13a and [15] questions the existence of a fatigue threshold for naturally occurring cracks. The value of the fatigue threshold, $\Delta \mathrm{K}_{\mathrm{thr}}=$ $0.1 \mathrm{MPa} \sqrt{\mathrm{m}}$, was taken to be that determined in [23] for the corroded bridge steel tests on samples taken from Kilmore East Bridge. As such equation (6) essentially reduces to the strain energy density crack growth equation presented in $[17,18]$.

The next stage of this study was to use the finite element model to compute crack growth. The loading applied to model was based on the worse case when an ore train (Included one $G$ Class locomotive and 20 fully loaded wagons) go over the bridge. The G Class locomotive has the following specifications: Total weight $=128$ tonnes, axle loading $=21.3$ tonnes, wheel base $=3810 \mathrm{~mm}$, axle spacing $=1905 \mathrm{~mm}$ and leading wheel leading bogie to leading wheel trailing bogie $=12622 \mathrm{~mm}$. Due to symmetry considerations, only quarter of the wheel was modelled. The resultant mesh, which was created using software program FEMAP [25], had 18146 twenty-one-noded elements and 91590 nodes (with 274770 degrees of freedom), see Figures 28 and 29. The stresses at critical region are in good agreement with the results from field strain gauges measurement [26].

The Equations 2 to 6 consequently used to do crack growth analysis in this paper. Here, it is allowing for changes in the section thickness as the section corrodes.

The resultant crack growth results are given in Figures 30. In this analysis, if the crack growth in a year is less than $0.024 \mathrm{~mm}$, it is assumed that the crack has been "eaten" by corrosion. In this analysis, the initiating (inherent) crack was taken from [23], which tested a section from a condemned and badly corroded steel bridge, to be a $0.05 \mathrm{~mm}$ deep semicircular initial crack. The section thickness is reduced accordingly and the stresses increased. This analysis yielded a life to failure of approximately 116 years. There is a difference of $\sim 28.9 \%$ in the computed fatigue life between the no corrosion and with corrosion effect case. Since the life of the bridge is a strong function of the size of the initiating defect, the analysis was repeated for a range of initial crack sizes and the resulting lives are shown in Figures 3031. The percentage difference between the case of no corrosion and with corrosion effect reduced as the size of initial crack increased.

\section{CONCLUSIONS}

This data presented in this paper supports the ASHTO recommended metal loss model. The paper also presents a methodology for computing the growth of cracks that arise due to 
natural corrosion in bridge steels. It is shown that the durability of bridge structures becomes a competition between crack growth during operational loading and the loss of material due to corrosion.

From the analysis provided in this paper, it is revealed that failure assessment of steel bridges needs to account for the interaction between fatigue crack growth and the increase in stress, that arises from the corrosion process, due to the reduction in the section thickness. The methodology described in this paper is ideal for use in steel bridges. It allows accurate results to be obtained without the need to explicitly model a crack. However, it is still necessary to model the uncracked structure.

\section{REFERENCES}

1. AREMA Bridge Inspection Handbook: Railway Track \& Structures, USA 2016.

2. R. Akid, T. Richardson, Corrosion Fatigue. In Shreir's Corrosion. (Vol. 2, pp. 928-953), 2010.

3. M. R. Ayatollahi, S. M. J. Razavi, H. R. Chamani, A numerical study on the effect of symmetric crack flank holes on fatigue life extension of a SENT specimen. Fatigue \& Fracture of Engineering Materials \& Structures, 37, 10, pp. 1153-1164 (2014).

4. M. R. Ayatollahi, S. M. J. Razavi, M. Y. Yahya MY, Mixed mode fatigue crack initiation and growth in a CT specimen repaired by stop hole technique. Engineering Fracture Mechanics, Vol. 145, pp. 115-127 (2015).

5. S. M. J. Razavia, M. R. Ayatollahia, C. Sommitsch, C. Moser, Retardation of fatigue crack growth in high strength steel S690 using a modified stop-hole technique, Engineering Fracture Mechanics, Vol. 169, pp. 226-237 (2017).

6. X. L. Zhao, L. Zhang, State-of-the-art review on FRP strengthened steel structures, Engineering Structures, 29, 8, pp. 1808-1823, 2007.

7. K. Ali, RRK. Singh, XL. Zhao, R. Jones and A. J. McMillan., Composite repairs to bridge steels demystified, Journal of Composite Structures, 2016, Volume 169, 1, 2017, pp. 180189.

8. D. N. Adasooriya, Fatigue reliability assessment of ageing railway truss bridges: Rationality of probabilistic stress-life approach, Case Studies in Structural Engineering 6 (2016) 1-10.

9. N. D. Adasooriya and S. C. Siriwardane, Remaining fatigue life estimation of corroded bridge members, Fatigue. Fract. Engng. Mater. Struct. 37 (2014) 603-622.

10. W.T.M.S.M. Wanninayake, W.M.P.R. Wasala, C.S. Bandara, Life evaluation of critical members of steel bridges located in different atmospheres, Proceedings of the $6^{\text {th }}$ International Conference on Structural Engineering and Construction Management, Kondy, Sri Lonko, Dec 11-13, 2015.

11. T. Q. Zhou, T.H.T. Chan, Y. Hua, Fatigue Damage Analysis on Crack Growth and Fatigue Life of Welded Bridge Members with Initial Crack, Key Engineering Materials 324-325 (2006) 251-254.

12. A. Carpinteri, C. Ronchei, S. Vantadori, Stress intensity factors and fatigue growth for surface cracks in notched shells and round bars: two decades of research work. Fatigue and Fracture of Engineering Materials and Structures 36, 11 (2013), pp. 1164-1177.

13. A. Carpinteri, C. Ronchci, D. Scorza, S. Vantadori, Fracture mechanics based approach to fatigue analysis of welded joints. Engineering Failure Analysis 49 (2015), pp. 67-78.

14. D. Peng, C. Wallbrink, R. Jones, Stress intensity factor solutions for finite body with quarter-elliptical flaws emanating from a notch. Eng. Fract. Mech. 72 (2005) 1329-1343. 
15. R. Jones, Fatigue crack growth and damage tolerance, Fatigue. Fract. Engng. Mater. Struct. 37 (2014) 463-483.

16. R. Jones, D. Peng, S. Pitt, C. Wallbrink, Weight Functions, CTOD, and Related Solutions for Cracks at Notches, Engineering Failure Analysis 11 (2004) 79-36.

17. F. Berto, A. Campagnolo, F. Chebat, M. Cincera, M. Santini, Fatigue strength of steel rollers with failure occurring at the weld root based on the local strain energy values: modelling and fatigue assessment, International Journal of Fatigue, 82 (2016) 643-657.

18. F. Berto, P. Lazzarin, Recent developments in brittle and quasi-brittle failure assessment of engineering materials by means of local approaches, Materials Science and Engineering R, 75 (2014) 1-48.

19. K. L. Fishman, J. L. Withiam, LRFD Metal Loss and Service-Life Strength Reduction Factors for Metal-Reinforced Systems, NCHRP 675, Transportation Research Board, Washington, DC, 2011.

20. AASHTO, LRFD Bridge Design Specifications, 4th Ed. With Interims, American Association of State Highway and Transportation Officials, Washington, D.C. 2009.

21. ISO 9224: Corrosion of metals and alloys - Corrosivity of atmospheres - Guiding values for the corrosivity categories. Published in Switzerland, 2012.

22. P. Albrecht, Jr T.T. Hall, Atmospheric Corrosion Resistance of Structural Steels, Journal Of Materials In Civil Engineering 15 (2003) 1-24.

23. K. Ali, D. Peng, R. Jones, R. R. K. Singh, X. L. Zhao, A. J. McMillan, F. Berto, Crack growth in a naturally corroded bridge steel, Fatigue \& Fracture of Engineering Materials \& Structures, 40, 7 (2017), pp. 1117-1122.

24. Bridge Design Australian Standard, AS 5100.2-2004.

25. FEMAP - Finite Element Modelling and Post Processing, Version 11.1.2, Structural Dynamics Research Corporation, Pennsylvania; 2015.

26. D. Peng, K. Cairns, Bridge 62 near Kilmore East Strain Gauge Data Analysis, Rail CRC report, Monash University, March, 2012.

27. L. F. Gillemot, Brittle fracture of welded materials. In: Commonwealth Welding Conference; 1965, C.7. 353-358.

28. L. F. Gillemot, E. Czoboly, I. Havas, Fracture mechanics applications of absorbed specific fracture energy: notch and unnotched specimens, Theor Appl Fract Mech, 1985; 4: $39-45$.

29. G. C. Sih, Strain-energy-density factor applied to mixed mode crack problems, Int J Fract $1974 ; 10: 305-32$.

30. G. C. Sih, Mechanics of Fracture Initiation and Propagation, Dordrecht: Kluwer Academic Publisher; 1991.

31. E. E. Gdoutos, Fracture Mechanics Criteria and Applications, Dodrecht: Kluwer Academic Publishers; 1990.

32. R. Badaliance, Application of strain energy density factor to fatigue crack growth analysis, Engineering Fracture Mechanics, 1980, 3, pp. 657-666.

33. Hart-Smith LJ., Adhesively bonded double lap joints, NASA Langley Research Center Report NASA CR-112235, January 1973.

34. Hart-Smith LJ., Adhesive bonded scarf and lap joints, NASA Langley Research Center Report NASA CR-112237, January 1973.

35. CMH-17-3G, Composite Materials Handbook, Volume 3: Polymer Matrix Composites Materials Useage, Design and Analysis, Published by SAE International, March 2012.

36. Jones R., Chiu WK. and Paul J., Designing for damage tolerant bonded joints, Composite Structures, 25, 201-207, 1993.

37. Chiu WK., Rees D., P. Chalkley and Jones R., Designing for damage tolerant repairs, Journal of Composite Structures, 28, 1, 19-38, 1994. 
38. Jones R., Sawyer J. and Chiu WK., Studies in the matrix dominated failures of composite joints, Journal of Composite Structures, 44, 1-16, 1999.

39. Jones R., Chapter 9, Numerical Analysis and Design, in Advances in the Bonded Composite Repair of Metallic Aircraft Structure, Edited by A. Baker, L. R. F. Rose and Jones R., Elsevier Applied Science Publishers, 2002. ISBN 0-08-042699.

40. Jones R., Kotousov A. and Marshall IH., Adhesively bonded joints under cyclic load spectra, Fatigue and Fracture of Engineering Materials and Structures, 25, 1-13, 2002.

41. Teodosiadis, R., Plastic Analysis of Bonded Composite Lap Joints, Douglas Aircraft Company, IRAD Report No. DAC-67836, May 1969.

42. R. Jones, D. Tamboli, (2013) Implications of the lead crack philosophy and the role of short cracks in combat aircraft, Engineering Failure Analysis, 29.149-166.

43. Zonker HR., Bray GH., George K., Garratt MD., Use of ACR Method to Estimate Closure and Residual Stress Free Small Crack Growth Data, (2005) Journal of ASTM International, July/August 2005, Vol. 2, No. 7, Paper ID JAI12023, available online at www.astm.org

44. G. C. Sih, P. C. Paris, and G. R. Irwin, (1965) On cracks in rectilinearly anisotropic bodies, International Journal of Fracture Mechanics, 1, 3, pp.189-203.

45. R. Jones, A.J. Kinloch, W. Hu, Cyclic-fatigue crack growth in composite and adhesivelybonded structures: The FAA slow crack growth approach to certification and the problem of similitude, International Journal of Fatigue, 88, 2016, pp. 10-18. 


\section{APPENDIX: STRAIN ENERGY DENSITY AND FATIGUE CRACK GROWTH}

Strain energy density has long been used as a failure criteria for materials exhibiting both ductile and brittle behaviour [17, 18, 27-32]. It is also known to govern the failure of adhesively bonded joints and composite bonded scarf repairs to damaged composite structures [33 - 35]. In this context [33, 34] stated:

i) "The adhesive shear strain energy per unit bond area was the necessary and sufficient adhesive characteristic governing the potential bond shear strength."

ii) "The precise shape of the stress-strain curve appeared to be unimportant." This conclusion was supported by independent finite element studies [36-41].

When applied to crack growth there are currently two different variants. One approach expresses da/dN as a function of $\Delta \mathrm{S}$, where $\mathrm{S}=\mathrm{rW}$ and $\mathrm{r}$ is the distance from the crack tip, so that for Mode I growth $\mathrm{da} / \mathrm{dN}$ is expressed as a function of $\Delta\left(\mathrm{K}^{2}\right)$ [30-32]. The other approach expresses da/dN as a function of $\Delta \sqrt{ } \mathrm{S}$, or alternatively $\Delta \sqrt{\mathrm{W}}$, so that for Mode I growth $\mathrm{da} / \mathrm{dN}$ is expressed as a function of $\Delta \mathrm{K}$ [17-32]. Appendix X3 in the ASTM fatigue test standard E647-13a states:

"Fatigue cracks of relevance to many structural applications are often small or short for a significant fraction of the structural life. The growth rates of such cracks usually cannot be measured with the standard procedures described in the main body of Test Method E647, which emphasizes the use of large, traditional fracture mechanics specimen geometries."

With this in mind and noting that this paper focuses on the interaction of corrosion with small naturally occurring cracks let us consider the small and large $\mathrm{da} / \mathrm{dN}$ versus $\Delta \mathrm{K}$ data presented in [15] for crack growth in 7050-T7451 aluminium alloy, see Figure A1. The R = 0.33 data shown in Figure A1 is from [43]. The NASA $\mathrm{R}=0.4$ data is from the Nasgro data base. The initial crack lengths associated with the small crack data lie between approximately 3 microns up to 20 microns and the final crack length are of the order of $10 \mathrm{~mm}$.

Here we see that, as noted in $[15,42]$, the growth of small cracks essentially conforms to a Paris like equation and is largely $\mathrm{R}$ ratio independent. However, plotting the data as a function of $\Delta\left(\mathrm{K}^{2}\right)$ transforms Figure A1 to a near chaotic plot, see Figure A2. It also makes it appear that for a given value of the crack driving force, which in this instance is $\Delta\left(\mathrm{K}^{2}\right)$, tests performed at $\mathrm{R}=0.1$ are more severe than tests at $\mathrm{R}=0.7$ even though the later will have a greater $\mathrm{K}_{\max }$ value. The observation that for a given $\Delta \mathrm{W}$ tests at low $\mathrm{R}$ ratio's are more severe than tests at high R ratio's also follow from the crack growth data presented in [32]. This implication is counter intuitive. As such it would appear that it is best to relate da/dN to $\Delta \sqrt{ } \mathrm{W}$ $(\Delta \sqrt{ } \mathrm{S})$ rather than to $\Delta \mathrm{W}(\Delta \mathrm{S})$.

For pure Mode I and Mode II delamination growth in composites the energy release rate G is directly related to the strain energy density $\mathrm{W}$ [44]. Consequently this conclusion mirrors that given in [45] for Mode I and Mode II delamination growth where it is also noted that for delamination growth it is best to express $\mathrm{da} / \mathrm{dN}$ as a function of $\Delta \sqrt{ } \mathrm{G}$ rather than to $\Delta \mathrm{G}$ and that expressing da/dN as a function of $\Delta \mathrm{G}$ can lead to anomalous results. 